\title{
Animal Models of Colitis-Associated Carcinogenesis
}

\author{
Manasa Kanneganti, ${ }^{1}$ Mari Mino-Kenudson, ${ }^{2}$ and Emiko Mizoguchi, ${ }^{1,3}$ \\ ${ }^{1}$ Gastrointestinal Unit, Department of Medicine, Harvard Medical School, Massachusetts General Hospital, GRJ 702, 55 Fruit Street, \\ Boston, MA 02114, USA \\ ${ }^{2}$ Department of Pathology, Harvard Medical School, Massachusetts General Hospital, GRJ 702, 55 Fruit Street, Boston, \\ MA 02114, USA \\ ${ }^{3}$ Center for the Study of Inflammatory Bowel Disease, Harvard Medical School, Massachusetts General Hospital, GRJ 702, \\ 55 Fruit Street, Boston, MA 02114, USA
}

Correspondence should be addressed to Emiko Mizoguchi, emizoguchi@partners.org

Received 27 September 2010; Revised 8 December 2010; Accepted 10 December 2010

Academic Editor: Andrea Vecchione

Copyright ( $\odot 2011$ Manasa Kanneganti et al. This is an open access article distributed under the Creative Commons Attribution License, which permits unrestricted use, distribution, and reproduction in any medium, provided the original work is properly cited.

Inflammatory bowel disease (IBD) is a group of chronic inflammatory disorders that affect individuals throughout life. Although the etiology and pathogenesis of IBD are largely unknown, studies with animal models of colitis indicate that dysregulation of host/microbial interactions are requisite for the development of IBD. Patients with long-standing IBD have an increased risk for developing colitis-associated cancer (CAC), especially 10 years after the initial diagnosis of colitis, although the absolute number of CAC cases is relatively small. The cancer risk seems to be not directly related to disease activity, but is related to disease duration/extent, complication of primary sclerosing cholangitis, and family history of colon cancer. In particular, high levels and continuous production of inflammatory mediators, including cytokines and chemokines, by colonic epithelial cells (CECs) and immune cells in lamina propria may be strongly associated with the pathogenesis of CAC. In this article, we have summarized animal models of CAC and have reviewed the cellular and molecular mechanisms underlining the development of carcinogenic changes in CECs secondary to the chronic inflammatory conditions in the intestine. It may provide us some clues in developing a new class of therapeutic agents for the treatment of IBD and CAC in the near future.

\section{Introduction}

Crohn and Rosenberg first reported the UC case associated with colorectal cancer development in 1925 [1], and the association between colitis and colorectal cancer is widely accepted currently. It is assumed that chronic inflammation is a direct cause of CAC; however, it is not until 10 years after disease onset when a risk of colon cancer development in IBD patients becomes significant. The risk is approximately five times higher than in the general population. Eaden et al. reported that the cumulative incidence of colorectal cancer in UC patients was $2 \%$ at 10 -year, $8 \%$ at 20 -year, and $18 \%$ at 30 -year with followup study [2]. The important risk factors include family history of colon cancer, disease duration/extent, and concurrent primary biliary cholangitis $[3,4]$. The cancer risk seems to be closely associated with the extent of colonic involvement and length of time since disease onset [5]. To detect microscopic foci of dysplasia or early stage of cancer, IBD patients need to undergo an annual colonoscopy with multiple biopsies. A minimum of 33 samples and a total of 50 or more biopsies will be necessary to achieve a high confidence (90\%-95\%) of detecting cancerous region(s) $[6,7]$. A tremendous amount of effort is currently being directed toward improving colonoscopic technology and developing genetic and serological markers [8]. At this time, however, only a limited amount of data are available for understanding the exact mechanisms of how chronic colitis is connected to the development of colorectal tumors.

The small and large intestines both contain an abundance of luminal antigens, including food products and enteric microorganisms. Intestinal epithelial cells provide an important barrier between the potentially hazardous luminal contents and immune cells in the situated lamina propria $[9,10]$. The function of colonic epithelial cells 
(CECs) is tightly regulated by many soluble factors derived from enteric bacteria and epithelial cells themselves [11, 12]. CECs actively participate in the detoxification and biotransformation of xenobiotics [13, 14], and the failure of these important functions leads to epithelial cell injury and intestinal inflammation [15]. The development or perpetuation of intestinal inflammation is also closely associated with the induction of several molecules on CECs including Tolllike receptors (TLRs) and tumor necrosis factor receptors (TNFRs) [14, 16, 17]. So far, many animal models of chronic colitis and colitis-associated cancer (CAC) provide evidence that a variety of inflammatory mediators play pivotal and specific roles in the initiation and development of colitis and CAC [18]. In particular, TNF and TNFR ligation activated $\mathrm{NF}-\kappa \mathrm{B}$ and its downstream cell survival pathways seem to highly contribute to the development of colorectal carcinoma [19]. IL-6 is another important cytokine which controls the transition between innate and acquired immune responses [20], and increased levels of IL-6 have been detected both in human colon cancer patients and murine models of CAC [21]. In addition, mRNA expression of CC-chemokines including CCL-2 (MCP-1) is highly upregulated in the colonic mucosa of IBD patients as well as in the AOM pretreated DSS-colitis model [22-24]. Our group recently identified that one of the mammalian chitinases, chitinase 3-like-1 (CHI3L1/YKL-40), is significantly upregulated in message and protein levels in the colonic mucosa of IBD patients with active inflammation as well as murine models of colitis, [14] and this molecule seems to play an active role in the neoplastic transformation of epithelial cells $[25,26]$. Therefore, inflammatory cell infiltration and their secreting soluble mediators are key players in regulating pre-neoplastic growth of CECs in colitis-associated tumorigenesis.

In this paper, we have concisely summarized the previously reported animal models of CAC and will discuss possible roles of inflammatory mediators and their receptors in the chronically inflamed colonic mucosa during the development of chronic inflammation and CAC.

\section{Overview: Differences between Sporadic Colon Cancer and CAC}

Sporadic colorectal cancer, the major form of colon cancer, occurs in people with little or no family history of the disease. This type of cancer often arises from successive accumulation of mutations in genes controlling epithelial cell growth and differentiation. Genomic instability is important to the development of colon cancer; however, the process that causes this genomic instability is not completely understood. Two major types of genomic instability, chromosomal instability and microsatellite instability (MSI), contribute to colonic carcinogenic processes. MSI-positive colorectal carcinomas can be further divided into those with high (MSI-H) or low (MSH-L) levels of MSI depending on how many markers are unstable on a consensus panel [27]. High-level MSI accounts for approximately 15\% of sporadic colorectal cancers, while the remaining $85 \%$ are attributed to chromosomal instability [28]. MSI-H colorectal cancers neither exhibit gross cytogenetic abnormalities nor display allelic losses at tumor suppressor loci frequently, and they are not generally aneuploid. Colorectal carcinomas originating by the suppressor and mutator pathways differ in pathological features [29]. These tumors are likely to be present in the proximal colon, demonstrate poor differentiation, have mucinous or medullary features, and display more prominent lymphocytic infiltration compared to microsatellite stable tumors or MSI-L tumors.

As described above, colorectal cancer can be caused by chromosomal instability. This is characterized by widespread imbalances in chromosome number (aneuploidy), caused by defects in chromosomal segregation. Mutations in specific tumor suppressor genes and oncogenes that activate pathways critical for cancer development, which are important for the initiation and progression through the cell cycle, are seen in colorectal cancer $[30,31]$. The mitotic checkpoint (the spindle assembly checkpoint) is a major cell-cycle control mechanism that ensures proper chromosome segregation by delaying anaphase progression until all pairs of chromosomes are properly aligned on the metaphase plate. Defects in checkpoint signaling lead to chromosome missegregation and subsequent aneuploidy with abnormal numbers of chromosomes being distributed to daughter cells [32]. The products of two genes, mitotic arrest-deficient (MAD) and budding uninhibited by benzimidazoles (BUB), operate as checkpoint sensors and signal transducers that control sister chromatid separation. The activation of these leads to inhibition of the anaphase-promoting complex (APC/C), a large ubiquitin-protein ligase, and cell-cycle arrest. MAD3/BUBR1, MAD2, and BUB3 associate with APC/Cactivating molecule CDC20 to form the mitotic checkpoint complex and induce a conformational change in APC/C, which prevents binding and ubiquitination of its substrates [33]. The APC/C activation leads to degradation of securin (a protein involved in control of the metaphase-anaphase transition and anaphase onset) and activation of separases (a class of caspase-related proteases). Separase regulates a multiprotein complex termed cohesin, which creates physical links between sister chromatids that are maintained until late mitosis. The errors in this system lead to unequal chromosomal segregation [34]. In colorectal cancer, mutations have been found in hZw10, hZwilch/FLJ10036, and hRod/KNTC, which are kinetochore proteins that function at the spindle checkpoint. Another mutation is observed in Ding gene, which regulates proper chromosome disjunction [35].

Another mechanism leading to chromosome instability is abnormal centrosome number and function. Centrosomes coordinate mitosis by serving as an anchor for the reorganization of cytoplasmic microtubules into a mitotic spindle apparatus. When extra centrosomes are present, they lead to the formation of multiple spindle poles during mitosis, resulting in an unequal distribution of chromosomes. When centrosomes cluster, an increased rate of merotelic chromosomal attachment to spindle can cause chromosomal missegregation and ultimately chromosomal instability [36]. A third mechanism is a mutation in Aurora $\mathrm{B}$, a kinase regulating chromosome segregation. An overexpression of Aurora B correlates with advanced stages 
of colorectal cancer. This is the catalytic component of the chromosomal passenger complex that regulates accurate segregation of chromatids at mitosis, histone modification, and cytokinesis [37]. Finally, the elevated expression of PIK1 (a serine/threonine kinase which regulates entry into mitosis, centrosome duplication, and transition from metaphase to anaphase, and cytokines) is also observed in colorectal cancer $[38,39]$. All of these mutations lead to colorectal cancer through chromosomal instability and aneuploidy.

Chronic inflammatory diseases are associated with an increased risk of cancer, and IBD patients have a higher risk of developing CAC approximately 8-10 years after the initial diagnosis as compared to general population. In addition to genomic instability that underlies the process of tumorigenesis, continuous inflammation in the intestine seems to be a key factor in CAC development since chronic inflammation is associated with elevated levels of proinflammatory cytokines, chemokines, growth factors as well as their receptors, and reactive oxygen species. In particular, oxidative injury, causing widespread DNA damage, leads to the inception of cancer. Crypt fission (duplication of crypts by branching) propagates these heterogeneous DNA changes from one crypt to another. In fact, crypt fission is a natural way to duplicate the heterogeneous changes that are sometimes observed in the crypt units of UC patients. Eventually, some of these changes may induce a growth advantage and clonal expansion of CECs, and some of the mutational changes in one crypt can be found in thousands of adjacent crypts. The final stages of tumorigenesis in the chronic inflammatory setting occur when an accumulation of select mutations allows clonal progression to overtake the balancing forces of cell death and loss [40].

\section{Spontaneously Developed Animal Models of CAC}

A summary of CAC development in genetically engineered animal models of colitis has been shown in Table 1. We have further discussed some selected models, which are included or not included in Table 1, in this section. Although adenomatous polyposis coli (APC) multiple intestinal neoplasia (min) mice do not develop adenocarcinoma, these mice develop numerous adenomatous polyps throughout the small and large intestine, and therefore, we have included this model in the following section.

3.1. APC-Min Mice Model. APC is a multidomain protein translated from the APC gene and composed of 2843 amino acids, which functions to regulate downstream Wnt signaling by binding to $\beta$-catenin and promoting its degradation. APC, along with AXIN, GSK-3 $\beta$, EB1, and other proteins, forms a complex that binds to $\beta$-catenin. This complex formation prevents the nuclear translocation of $\beta$-catenin and causes its phosphorylation and, subsequently, its degradation by a proteasome. In this way, APC actually acts as a tumor suppressor gene by preventing the continuous activation of $\beta$-catenin. A mutation or loss of APC genes results in the upregulation of transcriptional targets such as c-myc and cyclin D1 [53].
Loss or mutation of APC is an early causative event in familial and sporadic colon cancer pathogenesis. The most common mutations in familial adenomatous polyposis (FAP) are deletions in codons 1309 (10\% occurrence) and 1061 (5\% occurrence) [54]. The mutations in these same codons account for $30 \%$ of germline mutations. The majority of germline mutations found in FAP patients are nonsense mutations, which cause the formation of a truncated protein because of the insertion of an early stop codon. Most of the mutations to APC represent truncating mutations, of which, $46 \%$ are small deletions, $10 \%$ are small insertions, $28 \%$ are nonsense mutations, and $13 \%$ are gross alterations. More than $60 \%$ of APC mutations are found in the mutation cluster region (MCR, amino acids 1284-1580), the region that is most important for the downregulation of $\beta$-catenin and for the pathogenesis of colorectal cancer. Many of these mutations lead to the generation of a truncated protein, which causes the loss of APC protein function [54, 55].

$\mathrm{APC}^{\mathrm{min}}$ mice, homozygous for the mutation, experience embryonic lethality. However, those that are heterozygous for the mutation are viable and develop more than fifty adenomas in the intestinal tract. The small intestine is most commonly the site of these tumors. These mice can also develop a variety of lesions in other organs such as desmoids tumors, epidermoid cysts, and mammary tumors [56]. Most $\mathrm{APC}^{\mathrm{min}}$ mice only survive to 120 days, at which point they die of the excess tumor formations in their small intestines [57]. In $\mathrm{APC}^{\mathrm{min} /+}$ mice, different areas of the gene, such as the EB1/RP1 binding area, DLG/PTP$\mathrm{BL}$ binding area, nuclear export/import signals, the CDK consensus phosphorylation site p34-cdc2 binding, the $\beta$ catenin binding site, $\beta$-catenin downregulation site, and Axin/conductin binding site, are missing by truncational mutations [55]. Because APC is an important molecule in the formation of colorectal cancer, mouse models have been developed to study the physiological and biological function of this protein in polyp formation. $\mathrm{APC}^{\mathrm{min} /+}$ mice have been widely utilized for studying the effects of this protein under controlled experimental conditions. $\mathrm{APC}^{\mathrm{min} /+}$ mice were treated with ethyinitrosourea (ENU) to induce colitis, and multiple intestinal neoplasia was observed carrying a nonsense mutation $[56,58]$.

The $\mathrm{APC}^{\mathrm{min}}$ mutation initiates mitotic defects in histologically normal crypt cells of the murine small intestine, in which misoriented spindles, misaligned chromosomes, and tetraploid cells are frequently observed. In addition, changes in crypt size, cell proliferation, and apoptosis have been observed [55]. The cells in these APC deficient crypts show reduced crypt to villus migration and differentiation. Chromosomal instability resulting in losses and/or gains of chromosomal regions and microsatellite instability, which results from mismatch repair deficiency, is another change observed in APC deficient mice. Microadenoma formation, visible in these mice, could result from DNA hypomethylation.

Secretory Phospholipase 2 (sPLA2) is a key enzyme involved in the release of arachidonic acid from membrane lipids in the synthesis of prostaglandins. The loss of sPLA2 increases APC driven tumorigenesis. In addition, PLA2g4 (group 4 cytosolic phospholipase A2 catalyzes the hydrolysis 
TABLE 1: Summary of CAC in genetically engineered animal models of colitis.

\begin{tabular}{|c|c|c|c|c|c|}
\hline Model & Characteristics & Tumor histology & Tumor location & Incidence of cancer & References \\
\hline IL-2 $x \beta_{2}-\mathrm{M}$ DKO & UC-like & Carcinoma & Rectum, colon & $\begin{array}{l}32 \% \\
\text { adenocarcinoma }\end{array}$ & Sohn et al., 2001 [41] \\
\hline IL-10 KO & $\begin{array}{l}\text { CD-like duodenitis, } \\
\text { colitis }\end{array}$ & Carcinoma & Colon, rectum & $\begin{array}{l}60 \% \\
\text { adenocarcinoma }\end{array}$ & $\begin{array}{l}\text { Shattuck-Brandt et al., } \\
2000[42]\end{array}$ \\
\hline RAG2 KO & $\begin{array}{l}\text { Induced by infecting } \\
\text { with } H \text {. hepaticus }\end{array}$ & $\begin{array}{l}\text { Dysplasia, tubular } \\
\text { adenoma, carcinoma, } \\
\text { adenocarcinoma }\end{array}$ & Cecum, colon & $\begin{array}{l}100 \% \\
\text { adenocarcinoma }\end{array}$ & Erdman et al., 2003 [43] \\
\hline $\mathrm{RAG} 2 / \operatorname{Tgf} \beta 1 \mathrm{DKO}$ & Colitis & $\begin{array}{l}\text { Dysplasia, } \\
\text { adenocarcinoma }\end{array}$ & Cecum, colon & $\begin{array}{l}100 \% \\
\text { adenocarcinoma }\end{array}$ & Erdman et al., 2003 [43] \\
\hline TCR $\beta /$ p53 DKO & UC-like & $\begin{array}{l}\text { Dysplasia, } \\
\text { adenocarcinoma }\end{array}$ & Ileocecum, cecum & $\begin{array}{l}70 \% \\
\text { adenocarcinoma }\end{array}$ & Kado et al., 2001 [44] \\
\hline Gpx1/Gpx2 DKO & Ileocolitis & $\begin{array}{l}\text { Dysplasia, } \\
\text { adenocarcinoma, } \\
\text { signet ring cell } \\
\text { carcinoma }\end{array}$ & Ileum, colon & $\begin{array}{l}28 \% \\
\text { adenocarcinoma }\end{array}$ & Chu et al., 2004 [45] \\
\hline $\mathrm{G}_{\alpha \mathrm{i} 2} \mathrm{KO}$ & UC-like & Carcinoma & Colon & $\begin{array}{l}31 \% \\
\text { adenocarcinoma }\end{array}$ & Rudolph et al., 1995 [46] \\
\hline Msh2 KO & HNPCC & $\begin{array}{l}\text { Adenoma, } \\
\text { adenocarcinoma }\end{array}$ & Jejunum & $\begin{array}{l}38.9 \% \\
\text { adenocarcinoma }\end{array}$ & Reitmair et al., 1996 [47] \\
\hline Msh3 x Msh6 DKO & HNPCC & $\begin{array}{l}\text { Adenoma, } \\
\text { adenocarcinoma, } \\
\text { lymphoma }\end{array}$ & GI tract & $\begin{array}{l}81.3 \% \\
\text { adenocarcinoma }\end{array}$ & Edelmann et al., 2000 [48] \\
\hline Msh6 KO & HNPCC & $\begin{array}{l}\text { Adenoma, } \\
\text { adenocarcinoma, } \\
\text { lymphoma }\end{array}$ & GI tract & $\begin{array}{l}38.5 \% \\
\text { adenocarcinoma }\end{array}$ & Edelmann et al., 2000 [48] \\
\hline Mlh1 KO & HNPCC & $\begin{array}{l}\text { Adenomas, } \\
\text { adenocarcinomas }\end{array}$ & GI tract & $\begin{array}{l}72.0 \% \text { tumor } \\
\text { incidence } \\
9.36 \% \\
\text { adenocarcinoma }\end{array}$ & Edelmann et al., 1999 [49] \\
\hline Mlh3 KO & HNPCC & $\begin{array}{l}\text { Adenomas, } \\
\text { adenocarcinomas }\end{array}$ & GI tract & $\begin{array}{l}52 \% \text { tumor } \\
\text { incidence } \\
14 \% \\
\text { adenocarcinoma }\end{array}$ & Chen et al., 2005 [50] \\
\hline Mlh3 x Pms2 DKO & HNPCC & $\begin{array}{l}\text { Adenomas, } \\
\text { adenocarcinomas }\end{array}$ & GI tract & $\begin{array}{l}42 \% \text { tumor } \\
\text { incidence }\end{array}$ & Chen et al., 2005 [50] \\
\hline Msh2 $2^{\mathrm{G} 674 \mathrm{~A} / \mathrm{G} 674 \mathrm{~A}}$ & HNPCC & Adenocarcinomas & GI tract & $\begin{array}{l}19 \% \\
\text { adenocarcinoma }\end{array}$ & Lin et al., 2004 [51] \\
\hline $\mathrm{Mlh}^{\mathrm{G} 67 \mathrm{R} / \mathrm{G} 67 \mathrm{R}}$ & HNPCC & $\begin{array}{l}\text { Adenocarcinoma, } \\
\text { adenoma, squamous } \\
\text { basal cell carcinoma }\end{array}$ & GI tract & $\begin{array}{l}61 \% \\
\text { adenocarcinoma }\end{array}$ & Avdievich et al., 2008 [52] \\
\hline
\end{tabular}

Abbreviations: CD, Crohn's disease; DKO, double knockout; GI, gastrointestinal; HNPCC, hereditary nonpolyposis colorectal cancer; KO, knockout; RAG, recombination-activating gene: UC, ulcerative colitis.

of membrane phospholipids to release arachidonic acid) suppresses tumor multiplicity in $\mathrm{APC}^{\mathrm{min} /+}$ [57]. Although $\mathrm{APC}^{\mathrm{min} /+}$ mouse is a good model of colitis, there are differences between the progression of disease in mice and humans. In $\mathrm{APC}^{\mathrm{min} /+}$ mouse model, the polyp formation occurs mainly in the small intestine, while this formation occurs mainly in the colon in humans. In addition, there is very little or no invasion of the submucosa by tumors in $\mathrm{APC}^{\mathrm{min} /+}$ mice, and the tumors do not develop into adenocarcinomas [59].

$\mathrm{APC}^{\mathrm{min}}$ has interactions with other genes as well. Previous studies have shown that one of the downstream targets of Wnt signaling, cyclin D1, was not upregulated immediately after APC loss and did not contribute to the early phenotype in colon cancer. In contrast, the loss of both proto oncogene c-myc and APC has a crucial role in early stages of sporadic colorectal carcinoma development. As argued by some investigators, loss of APC function is typically an early stage event in the pathogenesis of sporadic colorectal carcinoma, but APC mutation itself seems to be a later stage (from high-grade dysplasia to adenocarcinoma) of tumor progression in CAC, suggesting APC mutation may not be the universal initiating event in colon cancer [27]. However, loss and/or truncation of APC still highly contributes to the cause of mitotic spindle defects that, upon somatic inactivation of other chromosomal instability 
genes (e.g., spindle and cell-cycle checkpoint genes, DNA repair, and telomerase maintenance), underlie aneuploidy as observed in the majority of colorectal cancer [60].

3.2. IL-10 Knockout (KO) Mice Model. IL-10 is a key regulator of the pathogenesis of IBD. Patients with mutated IL10 signaling systems show early and aggressive development of systemic inflammation including IBD. IL-10 KO mice also develop spontaneous colitis and CAC with aberrant Th1cytokine production. The histopathology of chronic colitis in IL-10 KO mice is characterized by epithelial hyperplasia, inflammatory infiltrates in the mucosa and submucosa, and crypt abscesses [61]. The inflammatory infiltrates consist of small to moderate numbers of neutrophils and eosinophils as well as lymphocytes, plasma cells, and macrophages, and may involve the intestine transmurally. Six-month-old mice showed other lesions characterized by irregular glands, back-to-back growth of glands, small nests of epithelial cells in the intestinal walls, fibrosis, and slight loss of nuclear polarity consistent with adenocarcinoma [61]. No metastasis in lymph nodes and liver were observed at this age [62]. Although the adenocarcinomas in IL-10 KO mice are histologically very similar to those seen in IBD patients, the lack of involvement of K-ras, p53, APC, and MSH genes indicates that IL-10 KO mice are not optimal for investigating IBD-associated carcinogenesis [63].

The development of CAC in IL-10 KO mice has been demonstrated in C57BL/6/129-Ola mixed background mice. These IL-10 KO mice have a 25\% incidence of developing adenocarcinoma after 3 months of age. After 6 months of age, they have a $60 \%$ incidence of adenocarcinoma [61]. Similarly, it was found in another study that IL-10 KO mice develop tumors, the majority of which are invasive adenocarcinomas, between 25 and 35 weeks of age [64]. Finally, a third study showed the incidence of adenocarcinomas was $14 \%$ at 9 weeks of age and $65 \%$ at $10-31$ weeks of age [62]. When recombinant IL-10 was administered to these mice, the incidence of adenocarcinoma decreased from $67 \%$ to $28 \%$. In addition, the background of the mice influences the incidence of adenocarcinoma; IL-10 KO Balb/c, IL-10 KO $129 \mathrm{SvEv}$, and IL-10 KO C57BL/6 have incidences of $29 \%, 67 \%$, and $0 \%$, respectively, at 3 months of age [39]. IL-10 KO mice in 129SvEv background showed epithelial extension/invasion mainly in the ascending colon and subsequently developed adenocarcinomas at 6 months of age without showing any signs of metastatic disease [65].

The development of adenocarcinoma in IL-10 KO mice seems to be associated with colonic bacterial infection [66]. IL-10 KO mice infected with Helicobacter typhlonius had a $40 \%$ incidence of invasive adenocarcinoma, and the pups born to these mothers, as well as mice infected as pups, had an $18 \%$ incidence of colon cancer. In contrast, mice infected with Helicobacter rodentium had a $0 \%$ incidence of invasive adenocarcinoma. Interestingly, however, pups born to these mothers and mice infected as pups had an incidence of $12 \%$. Finally, mice infected with both types of bacteria had a $57 \%$ incidence of invasive adenocarcinoma. It is hypothesized that the bacteria infect the mice by burrowing through the mucus to grow adjacent to the intestinal epithelial surface, where they degrade the barrier properties. This causes injurious leakage of bacterial antigens into the mucosa, which causes an immune response that in turn leads to the development of IBD and subsequently adenocarcinoma in the host [66].

$\mathrm{AOM}$ and DSS treatment promotes inflammationmediated colonic tumor growth in IL-10 KO mice [67]. Furthermore, Helicobacter hepaticus infection accelerates AOMinduced tumorigenesis compared to $\mathrm{AOM}$ treatment alone in IL-10 KO mice [68].

IL-10 KO mice crossed to human MUC1-transgenic mice developed much more severe colitis with a significantly higher incidence of colon cancer as compared to IL-10 KO mice [64]. MUC-1 has been reported to be overexpressed in IBD and adenocarcinoma, while its expression levels in normal and healthy CECs are low. Interestingly, vaccination against MUC1 delays IBD onset and also prevents CAC development in these mice, suggesting that the induction of MUC1-specific adaptive immune responses, such as antiMUC1 IgG and anti-MUC1 CTL, regulate local and systemic immunity by eliminating abnormal MUC1-positive cells in the IBD colon [64].

3.3. Gai2 KO Mice Model. G proteins (guanine nucleotidebinding proteins) are signal transducing proteins that couple a large family of receptors to effectors such as adenylyl cyclase, phospholipase C, and ion channels [69]. Receptoractivated $G$ proteins are subsequently bound to the inner surface of the cell plasma membrane, which consists of the $\mathrm{G} \alpha$ and $\mathrm{G} \beta \gamma$ subunits. There are four classes of $\mathrm{G} \alpha$ subunit, namely, $G \alpha S, G \alpha i, G \alpha q / 11$, and $G \alpha 12 / 13$. G $\alpha$ i inhibits the production of cAMP from ATP A C-terminal splice variant of $\alpha \mathrm{i} 2$, which localizes to the Golgi apparatus and could be involved in membrane transport [70]. The inhibition of adenylyl cyclase, stimulation of inwardly rectifying and ATP sensitive $\mathrm{K}+$ channels, regulation of fibroblast proliferation, stimulation of MAP kinase pathway, differentiation of F9 teratocarcinoma cells into primitive endoderm, and regulation of neonatal growth and development are all dependent on this [46]. To further analyze the biological function of $\mathrm{G}$ proteins in cellular signaling and cell differentiation, $\mathrm{KO}$ mice for G $\alpha$ i2 gene were generated by Rudolphs et al. [70]. These mice developed an IBD with clinical and histological features strikingly similar to UC, including the development

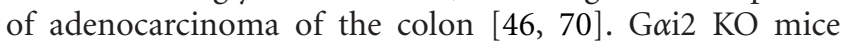
with colonic ulcerations had foci of regenerative proliferation of glandular epithelium through the full thickness of the mucosa and, in some foci, both the inflammation and glandular epithelium penetrated into the submucosa. Approximately $30 \%$ of mice showed highly atypical glands characterized by back-to-back growth without intervening stroma, loss of nuclear polarity, and marked crowding indicative of colon cancer; however, polypoid growths were not evident in these mice [46]. Migration of circulating leukocytes into the intestinal mucosa was partially dependent on $\alpha 4$ integrins, and short-term administration of anti $\alpha 4$ integrin antibodies was effective to attenuate intestinal inflammation in some animal models of colitis and human clinical trials [71-74]. 
However, Hornquist's group showed that long-term (three times/week for 9 weeks) blockade of $\alpha 4$ integrin significantly increased the severity of colitis as well as cancer incidence and also showed decreased levels of total IgA and IgG level in the sera of G $\alpha$ i2 $\mathrm{KO}$ mice [75]. Therefore, caution needs to be made upon applying a long-term treatment with anti- $\alpha 4$ integrin antibody in clinical trials.

\subsection{Chronic Colitis and CAC in Cotton Top-Tamarin (CTT).} CTT is one of the best primate models for studying colitis and CAC although it is not currently used because of the risk of extinction.

CTT was previously an important primate model for the study of colitis and CAC because, like humans, it spontaneously develops colitis which often leads to colorectal cancer. The CTT's natural habitat is a rain forest located in northwestern Colombia, South America [76]. CTT were initially imported to the United States in the 1960s and were used for infectious studies with Herpes samirii, Herpes ateles, and the Epstein-Barr virus. However, all research studies were withdrawn when the CTT were placed on the endangered species list in 1977. During the reconstruction effort of the CTT breeding colonies, it was found that chronic ulcerative colitis and colonic adenocarcinoma were to be major health problems for this species $[77,78]$. Approximately $80 \%$ of the captive CTT developed active colitis that would eventually lead to low-to-high grade dysplasia and colonic adenocarcinoma [76]. Another group also identified that $65.4 \%$ of captive CTT showed severe colitis but none in wild CTT, and $19.5 \%$ of captive CTT showed moderate colitis but only $13 \%$ in wild CTT [79]. In CTT, species-related susceptibility and infection (e.g., corona viruses, Campylobacter, Helicobacter, and enteropathogenic Escherichia coli) seem to be one of the causes of chronic colitis $[77,80]$. Other extrinsic/intrinsic factors include disruption of the immune system, family history of CTT, short-chain fatty acids (SCFAs), carcinoembryonic antigens (CEAs), and environmental stress. A unique member of Helicobacter is found in the intestines and feces of CTT with chronic colitis. This particular strain lacks urease activity and fails to hydrolyze alkaline phosphatase. The pathogenicity remains unknown, but since the Helicobacter family is considered to be responsible for inflammation and hyperplasia of epithelial cells and predisposes an individual to neoplasia, it is conceivable that this novel Helicobacter may play a role in contributing to UC and CAC of CTT [79].

Watkins et al. utilized a humanized anti-TNF $\alpha$ monoclonal antibody (CDP571) in treatment for the spontaneously developed colitis in CTT, and showed rapid improvement in clinical parameters [81]. This result strongly suggests that TNF $\alpha$ overproduction is likely a critical pathogenic factor in spontaneously developed chronic colitis in CTT. Several clinical studies have established that a chimeric (75\% mouse/25\% human) anti-monoclonal antibody (Infliximab) is beneficial in the treatment for IBD $[82,83]$. In particular, Infliximab is an effective maintenance therapy for fistulizing CD [84] and is useful for the treatment of mucosal ulceration associated with CD [83].
It is also noted that disrupting inflammatory mediators (neutrophils, lymphocytes, monocytes, eosinophils, and mast cells) are involved in the development of chronic colitis. Two research groups elegantly demonstrated that administration of monoclonal antibodies directed against either E-selectin or integrin $\alpha-4$ (one of the subunits of VLA4) attenuated colitis in CTT $[73,74]$. Since the followup animal studies by other groups also confirmed an important role of $\alpha-4$ integrins in the migration of circulating leukocytes into the intestinal mucosa, a clinical trial using Natalizumab (a humanized anti- $\alpha-4$ monoclonal antibody) for CD was initiated, and showed a statistically significant effect in the initial trial $[71,85]$. However, the following clinical trial could not confirm the benefit [86]. In addition, during the treatment with Natalizumab, some patients developed progressive multifocal leukoencephalopathy secondary to reactivation of the JC virus, a human polyomavirus that is typically acquired during childhood and remains latent in the kidneys and possibly other sites in up to $80 \%$ of the adult population [87]. Furthermore, blockade of $\alpha 4$ integrin exacerbated the chronic colitis and increased cancer incidence in a $\mathrm{G} \alpha_{\mathrm{i} 2} \mathrm{KO}$ mice model [75]. Based on these results, efficacy of Natalizumab for $\mathrm{CD}$ is highly questionable, and it carries a potential risk of severe complications [88].

\section{Chemically Induced Colitis-Associated Cancer Model}

4.1. Chronis DSS-Induced CAC Model. To reproduce the clinical course of UC experienced in humans, which is characterized by the spontaneous onset of active inflammation with separated periods of disease inactivity, DSS is administered for 3-7 days in mice to induce inflammation of the colon, followed by regular water administration for 1-2 weeks to permit healing of the colonic mucosa. Several "cycles" of DSS administration have also been used in order to augment carcinogenesis as observed in chronic ulcerative colitis patients. Squamous metaplasias of the rectal mucosa, squamous papilloma, adenoma, and adenocarcinoma have been observed in the treated mice. During the development of DSS-induced colorectal tumor, several genes, and molecules play pivotal roles in the pathogenesis. We have summarized some of the important factors in the following section as well as in Tables 2 and 3.

4.1.1. APC. The $\mathrm{APC}^{\mathrm{min} /+}$ mutation is found in $80 \%$ of sporadic colorectal cancers and is found in $4 \%-27 \%$ of CAC [109]. To test the effects of this gene on CAC development, colitis was induced in $\mathrm{APC}^{\mathrm{min} /+}$ mice. These $\mathrm{APC}^{+/ \mathrm{min}}$ mice (C57BL/6J strain) were treated with 2 cycles of DSS. The first cycle of DSS administration consisted of 4 days of $4 \%$ DSS followed by 17 days of regular water. The second cycle consisted of 3 days of 4\% DSS followed by 18 days of regular water. In another experiment, the mice (female, B6 background) were treated with 4 cycles of DSS with each cycle consisting of 4 days of $4 \%$ DSS and 17 days of regular water. Through these treatments, a two-fold $(50 \%$ to $100 \%$ ) increase in tumor incidence was found [100]. 
TABLE 2: Summary of CAC in chemically induced colitis models.

\begin{tabular}{|c|c|c|c|c|}
\hline Models & Animal species & Treatment & Duration & Selected references \\
\hline Carrageenan & Rats & $\begin{array}{l}5 \%-10 \% \text { degraded } \\
\text { carrageenan in diet, } \\
\text { drinking water or by } \\
\text { stomach tube }\end{array}$ & $\begin{array}{l}2,6,9 \text { months or up } \\
\text { to } 24 \text { months }\end{array}$ & $\begin{array}{l}\text { Ashi et al., } 1978 \text { [89] } \\
\text { Oohashi et al., } 1981 \text { [90] } \\
\text { Ishioka et al., } 1987 \text { [91] } \\
\text { Tobacman, 2001 [92] Benard } \\
\text { et al., } 2010 \text { [93] }\end{array}$ \\
\hline \multirow{7}{*}{$\begin{array}{l}\text { Dextran Sulfate } \\
\text { Sodium (DSS) }\end{array}$} & $\mathrm{C} 57 \mathrm{Bl} / 6 \mathrm{~J}$ & $0.1 \%-0.4 \%$ DSS & 60 days & Chromik et al., 2007 [94] \\
\hline & $\mathrm{C} 57 \mathrm{Bl} / 6 \mathrm{~J}$ & $0.7 \%$ DSS & $\begin{array}{l}15 \text { cycles of: } 1 \text { week } \\
\text { DSS followed by } 10 \\
\text { days water }\end{array}$ & Kim et al., 2010 [95] \\
\hline & $\mathrm{C} 57 \mathrm{Bl} / 6 \mathrm{~J}$ & $2.5 \%$ DSS & $\begin{array}{l}12 \text { cycles of: } 7 \text { days } \\
\text { DSS followed by } 10 \\
\text { days water }\end{array}$ & Seril et al., 2002 [96] \\
\hline & Mice & $3 \%$ DSS & $\begin{array}{l}9 \text { cycles of: } 7 \text { days DSS } \\
\text { followed by } 14 \text { days } \\
\text { water }\end{array}$ & Okayasu et al., 2002 [97] \\
\hline & $\mathrm{C} 57 \mathrm{Bl} / 6 \mathrm{~J}$ & $4 \%$ DSS & $\begin{array}{l}4 \text { cycles of: } 4 \text { days DSS } \\
\text { followed by } 12 \text { days } \\
\text { water }\end{array}$ & Cooper et al. 2001 [98] \\
\hline & $\begin{array}{l}\text { Wister Rats } \\
\text { (Male) }\end{array}$ & $5 \%$ DSS & $\begin{array}{l}5-8 \text { cycles of: } 4 \text { days } \\
\text { DSS followed by } 10 \\
\text { days water }\end{array}$ & Kullmann et al., 2001 [99] \\
\hline & $\begin{array}{l}\text { Swiss Webster } \\
\text { mice }\end{array}$ & $5 \%$ DSS & $\begin{array}{l}7 \text { days DSS followed } \\
\text { by } 14 \text { days water, } \\
\text { sacrificed } 120 \text { days } \\
\text { after the } 4 \text { th cycle }\end{array}$ & Cooper et al. 2000 [100] \\
\hline DSS \& AOM & $\begin{array}{l}\text { Mice } \\
(\mathrm{ICR}, \mathrm{Balb} / \mathrm{c} \text {, } \\
\mathrm{C} 57 \mathrm{Bl} / 6 \mathrm{~J})\end{array}$ & $\begin{array}{l}\text { AOM }(10 \mathrm{mg} / \mathrm{kg} \text { of } \\
\text { body weight) \& } 2 \% \\
\text { DSS in drinking } \\
\text { water }\end{array}$ & $\begin{array}{l}\text { Single IP AOM } \\
\text { injection followed by } \\
1 \text { week } 2 \% \text { DSS }\end{array}$ & $\begin{array}{l}\text { Tanaka et al., } 2003[101] \\
\text { Rosenberg et al., } 2009 \text { [102] } \\
\text { Tanaka and Yasui, } 2008 \text { [103] }\end{array}$ \\
\hline DSS \& DMH & Mice (BALB/c) & $\begin{array}{l}1 \text { dose of DMH } \\
(20 \mathrm{mg} / \mathrm{kg} \text { of body } \\
\text { weight }) \& 3 \% \text { DSS } \\
\text { in drinking water }\end{array}$ & $\begin{array}{l}\text { Single IP DMH } \\
\text { injection followed by } \\
3 \text { cycles of } 3 \% \text { DSS }\end{array}$ & $\begin{array}{l}\text { Kohno et al., } 2005[104] \\
\text { Tanaka et al., } 2005 \text { [105] }\end{array}$ \\
\hline DSS \& Iron & Mice $(\mathrm{C} 57 \mathrm{Bl} / 6 \mathrm{~J})$ & $\begin{array}{l}2 \mathrm{X} \text { Fe or } 2 \mathrm{X} \mathrm{Fe}-\mathrm{NAC} \\
\text { diet \& } 0.7 \%-1 \% \\
\text { DSS }\end{array}$ & $\begin{array}{l}12 \text { or } 15 \text { cycles of DSS } \\
\text { ( } 1 \text { DSS cycle }=7 \text { days } \\
\text { DSS followed by } 10 \\
\text { days water) }\end{array}$ & $\begin{array}{l}\text { Seril et al., } 2002[96] \\
\text { Seril et al., } 2002 \text { [106] } \\
\text { Seril et al., } 2003 \text { [107] } \\
\text { Seril et al., } 2006 \text { [108] }\end{array}$ \\
\hline
\end{tabular}

Abbreviations: AOM, azoxymethane; DMH, 1,2-dimethylhydrazine; IP, intraperitoneal.

The untreated control $\mathrm{APC}^{\mathrm{min} /+}$ mice had no evidence of invasive colorectal cancer while $40 \%$ of the DSS-treated $\mathrm{APC}^{\mathrm{min} /+}$ mice developed colorectal cancer. The incidence of adenocarcinoma in WT mice exposed to DSS was $12.5 \%$ and the mean number of tumors per tumor-bearing mouse was 1.0. All the DSS-treated WT mice had polypoid tumors with no evidence of flat lesions. These findings indicate that both the mutation of APC and inflammation accelerate the formation of colitis-associated dysplasia and their progression into invasive carcinoma. While inflammation is an augmenting factor for colorectal cancer development, loss of heterozygosity of the APC gene is also important in the formation of colorectal neoplasia [100].

4.1.2. $p 53$. The loss of $\mathrm{p} 53$ is one of the early mediators in CAC $[112,113]$. In the studies, DSS-colitis was induced in p53+/+, p53+/-, and p53 KO mice in C57Bl/6 background.
The mice were treated with 3 to 4 cycles of DSS followed by 120 days of regular water treatment after the final cycle of DSS administration. Each cycle consisted of 4 days of $4 \%$ DSS followed by 17 days of regular water. There were no colorectal lesions in untreated p $53+/+$, p $53+/-$ or $\mathrm{p} 53 \mathrm{KO}$ mice, while colorectal cancers developed in $57 \%$ of the DSS-treated p53 KO mice, $20 \%$ of p $53+/-$, and $20 \%$ of p $53+/+$. The DSStreated p53 KO mice had a larger number of lesions including cancers and dysplasias per mouse as compared to p53+/or p $53+/+$ mice. In the $\mathrm{p} 53 \mathrm{KO}$ group, $38.5 \%$ of the mice exhibited flat cancers, $46.1 \%$ flat dysplasias, $15.4 \%$ polypoid cancer, and $0 \%$ polypoid dysplasias. In contrast, the DSStreated $\mathrm{p} 53+/-$ mice showed more polypoid neoplasms: flat cancers were seen in only $16.7 \%$ of the mice, flat dysplasias in $0 \%$, polypoid cancers in $5.6 \%$, and polypoid dysplasias in $77.8 \%$. Interestingly, all the DSS-treated p $53+/+$ mice showed polypoid dysplasias. Therefore, flat cancers 
TABLE 3: Examples of CAC in genetically engineered mice with DSS treatment.

\begin{tabular}{|c|c|c|c|c|}
\hline Gene & Treatment & Cycles & $\begin{array}{c}\text { Invasive } \\
\text { carcinoma (\%) }\end{array}$ & References \\
\hline $\begin{array}{l}\text { Apc } \min +/- \\
\text { Apc min }+/-\end{array}$ & $\begin{array}{l}4 \% \text { DSS } \\
2 \% \text { DSS }\end{array}$ & $\begin{array}{l}2 \\
1\end{array}$ & $\begin{array}{c}40 \\
100\end{array}$ & $\begin{array}{l}\text { Makiyama et al., } 2005[110] \\
\text { Tanaka et al., } 2006[111]\end{array}$ \\
\hline $\begin{array}{l}\text { iNOS-/- } \\
\text { iNOS+/+ }\end{array}$ & $\begin{array}{l}1 \% \text { DSS + high } \\
\text { Iron }\end{array}$ & 15 & $\begin{array}{l}68 \\
65\end{array}$ & Van Assche et al., 2005 [87] \\
\hline $\begin{array}{l}\mathrm{P} 53-/- \\
\text { P53+/- } \\
\text { P53+/+ }\end{array}$ & $4 \%$ DSS & $3+120$ days & $\begin{array}{c}53.9 \\
22.3 \\
0\end{array}$ & Rutgeerts et al., 2006 [83] \\
\hline $\begin{array}{l}\text { Msh2-/- } \\
\text { Msh2+/- } \\
\text { Msh2+/+ }\end{array}$ & $5 \%$ DSS & $3-8$ & $\begin{array}{c}16.7 \\
8 \\
13.3\end{array}$ & Cooper et al., 2000 [100] \\
\hline $\begin{array}{l}\text { Brp39-1- } \\
\text { Brp39+/+ }\end{array}$ & $\mathrm{AOM}+3.5 \% \mathrm{DSS}$ & 3 & $\begin{array}{l}37.5 \\
87.5\end{array}$ & Segawa et al., 2010 [26] \\
\hline
\end{tabular}

Abbreviations: AOM, azoxymethane; APC adenomatous polyposis coli; DSS, dextran sulfate sodium; NOS, nitric oxide synthase; Brp39, breast regression protein 39 .

are highly associated with p53-deficient genotype while polypoid dysplasias are associated with $\mathrm{p} 53+/-$ and $\mathrm{p} 53+/+$ genotypes. In addition, nuclear translocation and mutation of $\beta$-catenin were observed only in polypoid lesions (91\% and $43.7 \%$, resp.). This result strongly suggests that the loss of p53 enhanced induction of CAC, and particular flat cancer-lesions, and dysregulation of $\beta$-catenin signaling plays an important role in the formation of polypoid-dysplastic lesions in the p53 model of colitis-associated neoplasia. Chang et al. used C57BL/6 x CBA mice and showed the similar results. After treatment with 2 cycles of $4 \%$ DSS (7days DSS treatment with 14 days interval), neoplastic lesions developed in $100 \%$ of $\mathrm{p} 53 \mathrm{KO}, 46.2 \%$ of p $53+/-$, and $13.3 \%$ of p53+/+ mice [114]. Invasive carcinoma was seen in 5\% of p53 KO mice. Furthermore, the majority of lesions in p53 $\mathrm{KO}$ were flat while those seen in $\mathrm{p} 53+/+$ mice were polypoid dysplasia. However, nuclear translocation of $\beta$-catenin was observed in both flat and polypoid neoplasias [115].

4.1.3. Inducible Nitric Oxide Synthesis (iNOS). iNOS activation causes prolonged production of $\mathrm{NO}$ at the cytotoxic level, and iNOS is overexpressed in colonic mucosa of UC patients and may contribute to pathogenesis of colitis associated neoplasia $[116,117]$. In one study, iNOS KO and iNOS+/+ mice (in C57BL/6 background) were treated with DSS (1\% DSS for 15 cycles, which consisted of 7 days DSS and 10 days interval with regular water per each cycle) and were fed with a high-iron diet AIN76A. Both groups developed well-differentiated adenocarcinomas in the intestine at the similar prevalence at the age of 255 days $(68.4 \%$ in iNOS $\mathrm{KO}$ and $65.2 \%$ in iNOS+/+ mice). The tumor multiplicity was also similar between the two groups $(2.0 \pm 0.2$ in iNOS $\mathrm{KO}$ and $1.5 \pm 0.2$ in iNOS $+/+$ mice). These results show that there is no difference in UC-associated cancer development in iNOS $\mathrm{KO}$ and iNOS $+/+$ mice, suggesting that in the absence of iNOS, the other two isoforms of NOS, endothelial NOS (eNOS) and neuronal NOS (nNOS), may take over the role of iNOS and may play a role in nitrosative stress and UCassociated carcinogenesis in this model [118].
4.1.4. Msh2. Msh2 is one of the mismatch repair genes that is frequently mutated in hereditary nonpolyposis colon cancer (HNPCC). It is unclear whether loss of mismatch repair contributes to development of colitis associated neoplasia in humans $[119,120]$. In a study, colitis was induced in Msh2 KO, Msh2+/-, and Msh2+/+ mice on a 12910LA x C57BL/6 background using DSS treatment. There was no difference in severity of chronic colitis as well as incidence of colonic neoplasms among the different genotypes. After 5 cycles of DSS treatment, $12.5 \%$ of Msh2 KO, $8.0 \%$ of Msh2+/-, and $46.7 \%$ of Msh2+/+ mice developed high-grade dysplasia. Similarly, colonic adenocarcinoma of the mucinous type were seen in $13.3 \%$ of Msh2 $\mathrm{KO}, 8.0 \%$ of Msh2+/-, and $16.7 \%$ of $\mathrm{Msh} 2+/+$ mice although the majority $(77.8 \%)$ of the Msh2 KO mice tumors were microsatellite instability high opposed to none of the Msh2+/- and Msh2+/+ mice. However, future studies using these mice may elucidate the role of the DNA mismatch repair in colitis-associated neoplasia in humans [121].

4.1.5. Brp39. Brp39 is a mouse homologue of Chitinase 3like-1 (CHI3L1, YKL-40, HC-gp39). CHI3L1 is induced on CECs and macrophages under inflammatory conditions and plays a key role in host-microbial interactions by enhancing the adhesion and invasion of bacteria into the CECs [122]. To examine the biological function of this molecule in the development of CAC, our lab has developed an AOMpretreated chronic DSS-induced CAC model using Brp39 KO and Brp39+/+ mice. Brp39 KO mice were more susceptible to the chronic DSS colitis with increased proinflammatory cytokine production and inflammatory cell infiltration in the colonic mucosa as compared to Brp39+/+ mice. Subsequently, the Brp39+/+ mice had a higher incidence of CAC (87.5\%) than Brp39 KO mice (37.5\%), suggesting that Brp39 plays a key role in the development of CAC.

4.2. Iron Supplemented DSS Model. Iron-deficiency anemia is a frequent complication in UC patients due to colorectal bleeding, and these patients are clinically treated with iron 
supplements [123]. However, Seril et al. reported that dietary iron supplementation enhanced the development of CAC in a 1\% DSS-induced colitis model, and the histology of the tumors was fairly similar to that of human CAC [96]. In the chronic DSS-treated mice, $88 \%$ of iron-enriched diet fed mice developed colorectal tumors while only 19\% of the control developed the tumors, suggesting that dietary iron may enhance the development of CAC in IBD patients presumably by augmenting oxidative and nitrosative stress $[96,108]$.

4.3. Carcinogen-Induced CAC Model. There are effective chemical agents, which directly or indirectly, induce colorectal tumors in laboratory animals. Many researchers use azoxymethane (AOM, methyl-mrthylimino-oxidoazanium), 1,2-dimethylhydrazine (DMH), and/or methyl azoxy methane (MAM) acetate in the animal models of CAC. AOM is the most widely used carcinogen in the colon. $\mathrm{AOM}$ - or DMH-induced colorectal cancer in rats shows many similarities to human colorectal cancer; however, there are some differences between the two. Although many human colorectal cancers arise from adenomatous polyps, $\mathrm{AOM}-$ or $\mathrm{DMH}$-induced rat adenocarcinoma in the colon develop in the background of flat mucosa without polyp formation [124]. In addition, it has been reported that the incidence of metastasis is relatively low in AOM- or $\mathrm{DMH}$-induced adenocarcinoma, while colorectal cancer patients have an approximate $50 \%$ metastatic rate in regional lymph nodes at the time of diagnosis [102]. Despite these differences, the chemical-induced CAC models are widely used, and have provided valuable information regarding the pathogenesis of CAC.

$\mathrm{AOM}$ is the oxide of azomethane and is used in cancer research to enhance the formation of colorectal tumors in rodents. AOM augments the expression of cyclooxygenase (COX)-2 (but not COX-1) in colonic tumors [125], which, in turn, suppresses transforming growth factor- $\beta$ receptor 2 (TGFBR2) expression in CECs [126] and activates intrinsic tyrosine kinase of epidermal growth factor receptor (EGFR) [127] in laboratory rodents. After treatment with subcutaneous or intraperitoneal injection of AOM $(10 \mathrm{mg} / \mathrm{kg}$ body weight, in general) followed by multiple cycles of DSS, the treated mice developed colonic tumors within a relatively short time period [101, 102]. AOM/DSS-induced colonic dysplasia and adenocarcinoma showed nucleic translocation of $\beta$-catenin and positive staining for COX-2 and inducible nitric oxide synthesis, but no immunoreactivity to p53 [128]. $\mathrm{AOM}$-treated $\mathrm{APC}^{\mathrm{min} /+}$ mice have also shown an enhanced expression of COX-2 in the early phase of colitis-associated tumors [42]. Interestingly, molecular analysis clearly demonstrated that AOM exposure induces the mutations in codons 33 and 34, while DSS exposure induces mutation in codon 32 of the mouse $\beta$-catenin gene [105]. A single dose of various colon carcinogens including $\mathrm{AOM}$ and $\mathrm{DMH}$, followed by exposure to 2\% DSS just for one week is effective enough to induce colonic tumors $[104,105]$, suggesting that there is no correlation between the severity of colitis and development of colonic tumors. Exposure to bacteria (by transferring from germfree to a specific pathogen free condition) followed by repeated AOM treatment for six times induces CAC in IL$10 \mathrm{KO}$ mice, but not in WT mice. The results support the notion that inflammation itself plays an important role in the initiation and progression of CAC [129].

4.4. Carrageenan-Induced CAC. Carrageenan (CGN) are high molecular weight $(>200 \mathrm{kDa})$ gelatinous polysaccharides, which are extracted from red seaweeds, and are widely used as thickening and stabilizing agents in the food or other industry products. Although the native form of OGN is thought to be harmless, a degraded form of CGN (so called Poligeenan or dCGN) with acid treatment at high temperature, around $80^{\circ} \mathrm{C}$, reduces the molecular weight $(<50 \mathrm{kDa})$ and may have toxic effects in animal models including rats, guinea pigs and monkeys by causing colonic ulceration and neoplasia in the gastrointestinal tract [92]. CGN-induced squamous metaplasia persisted in almost all experimental rats and progressed irreversibly, and the tumors included adenoma, adenocarcinoma, squamous cell papilloma, and squamous cell carcinoma [91]. However, the role of both CGN and dCGN as carcinogens still remains controversial. Tobacman's group demonstrated through in vitro studies that the native form of CGN induces IL-8 production in NCM460 human CEC line by enhancing the activation of NF- $\kappa B$ pathway $[130,131]$. Furthermore, dCGN induces cellular aggregation and enhances ICAM expression and TNF $\alpha$ production in monocytes through NF- $\kappa$ B activation both in vivo and in vitro [93]. These studies suggest that both native and degraded CGN may have a pronounced effect on the exertion of an inflammatory pressure on colonic mucosal cells including CECs and monocytes/macrophages.

\section{Involvement of Soluble Mediators in CAC}

A complicated immune network is involved in CAC development. To understand this mechanism in CAC, we have summarized the main interacting cells and soluble factors in Figure 1, and major signaling pathways involved in CAC development in Figures 2 and 3 . We have also summarized each major factor in CAC development in this section.

\subsection{Proinflammatory Cytokines/Factors}

5.1.1. TNF $\alpha$. TNF produces multiple effects including altered cell proliferation and cell death through distinct signaling cascades resulting from binding to TNFR type-I (TNFR1) and type-II (TNFR2) [132]. In general, cell death, altered target gene transcription, and cytokine production are mediated by TNFR1, while engagement of TNFR 2 has an antiapoptotic effect, acting through an NF- $\kappa$ B pathway [133]. These receptor-mediated signalings regulate inflammatory cell infiltration in the lamina propria, epithelial/mucosal damage, and cytokine expression in colonic mucosa in many animal models of colitis and CAC [18]. In fact, TNFR1 knockout (KO) mice showed a much milder form of colitis with a reduced incidence of CAC in response to the AOM pretreated DSS-induced colitis as compared to WT mice [134]. 


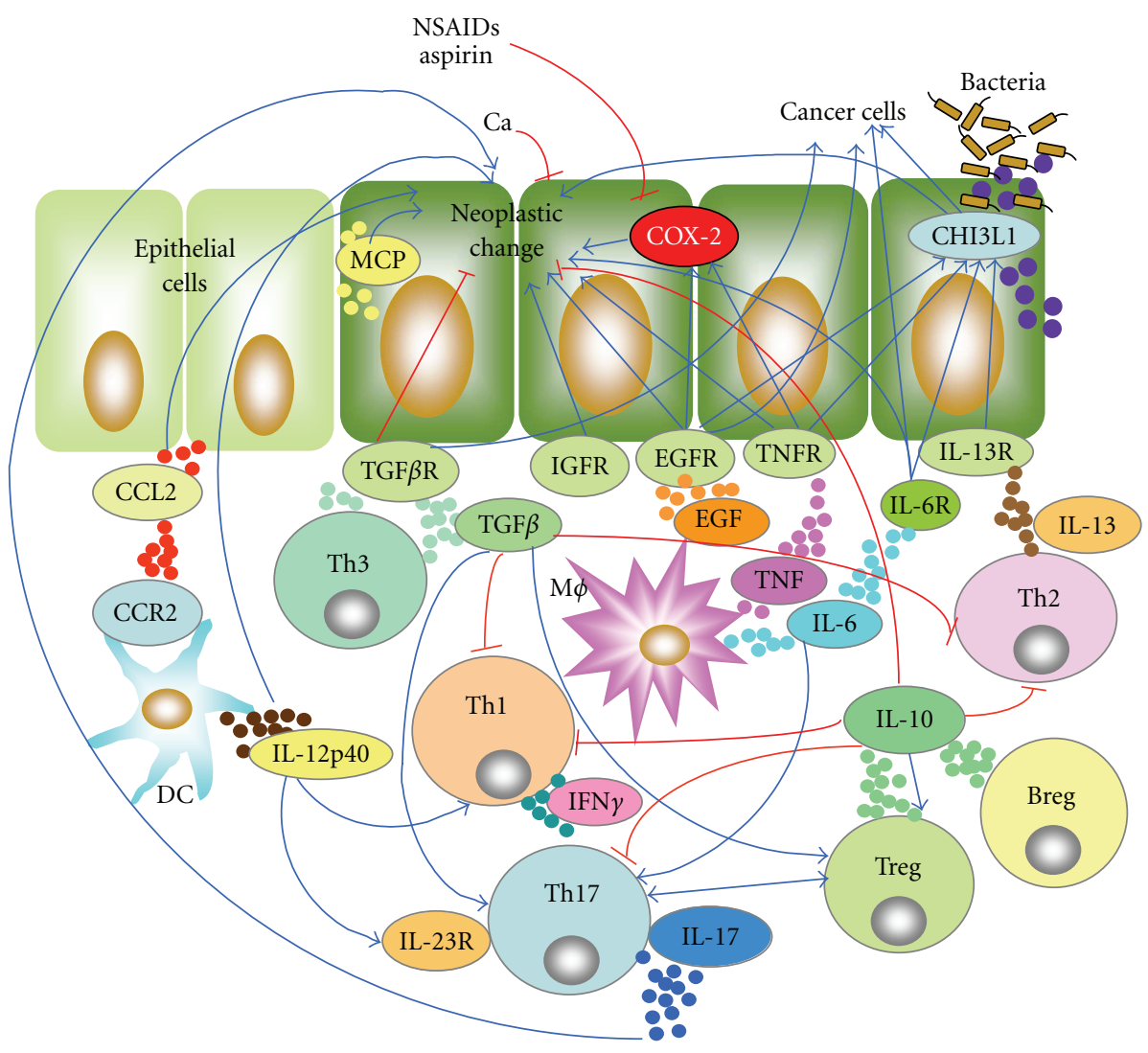

Figure 1: A complicated immune network in colitis-associated cancer (CAC). Previous and current data of CAC in animal models and in man suggest that many cell types as well as soluble factors are involved in the pathogenesis. High levels and continuous production of inflammatory mediators, including cytokines and chemokines by immune cells in lamina propria, may be strongly associated with the pathogenesis of CAC as shown in this figure. Although colonic epithelial cells (CECs) also produce a wide variety of cytokines and chemokines (e.g., IL-8, IL-23, TNF $\alpha$, TGF $\beta$, KC, MCP-1, and MIP1a) under inflammatory conditions and the following CAC development, these factors in CECs are not indicated here in order to simplify the figure. The abbreviations used in this figure are: Breg, regulatory B cells; $\mathrm{Ca}$, calcium, CCL2, chemokine (C-C motif) ligand 2; CCR2, chemokine (C-C motif) receptor 2; COX-2, cyclooxygenase-2; DC, dendritic cells; EGFR, endothelial growth factor receptor; IGFR, insulin-like growth factor receptor; IL, interleukin; MCP, monocyte-chemoattractant protein; $\mathrm{M} \phi$, macrophages; NSAIDs, nonsteroidal anti-inflammatory drugs; TGF, transforming growth factor; Th, T helper; TNFR, tumor necrosis factor receptor; Treg, regulatory T cells; CHI3L1, chitinase 3-like-1.

TNF initiates and perpetuates many inflammatory reactions and efficiently recruits activated inflammatory cells to the site of injury or inflammation [135]. TNF also efficiently activates NF- $\kappa \mathrm{B}$, MAPK and cell-death signaling pathways. Dysregulated TNF production has been identified in a various inflammatory disorders including rheumatoid arthritis, IBD, psoriasis, ankylosing spondylitis, and refractory asthma. TNF-blocking agents have been widely utilized for treatment of said disorders. In particular, these agents show a significant efficacy in refractory IBD compared to other anti-inflammatory and/or immunosuppressive medications [136]. Etanercept, a recombinant fusion protein consisting of the extracellular ligand-binding region of recombinant human TNFR attached to the constant $(\mathrm{Fc})$ region of human IgG1, binds to circulating TNF, inhibits its attachment to TNFRs, and efficiently blocks the TNF-mediated inflammatory pathway in rheumatoid arthritis [137]. However, while it efficiently blocks the tumor formation in AOMinduced CAC model, the efficacy of Etanercept in IBD is quite limited as compared to monoclonal antibodies directed against TNF $\alpha$ (e.g., Infliximab) [138]. In contrast, anti-TNF antibodies show unclear efficacy (anti- or procarcinogenic effects) in colorectal cancer development $[139,140]$.

5.1.2. IL-6. IL-6 (also known as IFN- $\beta$ or B-cell stimulator factor-2) plays an important role in the transition from acute inflammation to chronic colitis, as well as innate immunity to acquired immunity [141]. IL-6 is mainly produced by macrophages after being exposed to specific microbial molecules, so called pathogen associated molecular pattern (PAMPs). IL-6 binds to a cell-surface receptor complex, which consists of an IL-6R $\alpha$ chain (CD126) and the signal-transducing component gp130 (CD130). The ligandreceptor interactions initiate signal transduction cascades through transcription factors, Janus kinases (JAKs) and Signal Transducers and Activators of Transcription (STATs) [142]. In addition, IL-6 enhances the differentiation of 


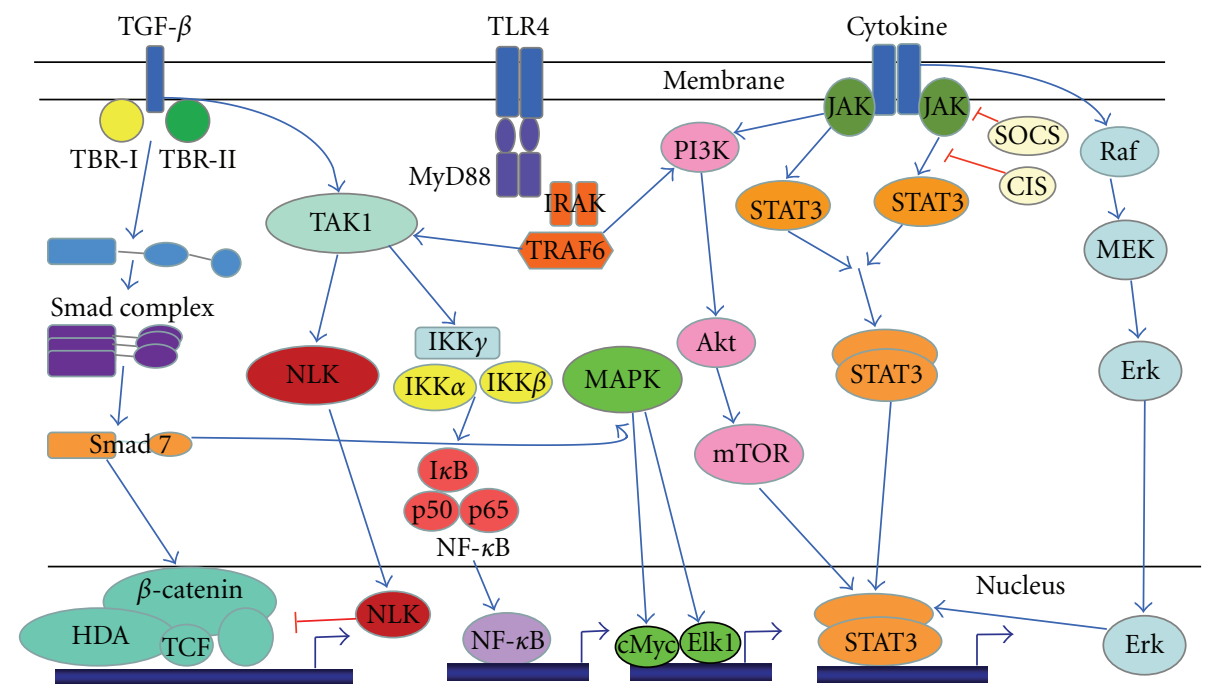

FIGURE 2: The JAK/STAT3 signaling pathway transmits information from cytokine/chemical signals outside the cell, through the cell membrane, and into the gene promoters on the DNA in the cell nucleus, which causes DNA transcription and activity in the cell. After JAK is activated by autophosphorylation, STAT3 protein then binds to the phosphorylated receptor. STAT3 is phosphorylated and translocated into the cell nucleus, where it binds to DNA and promotes transcription of genes responsive to STAT. TGF- $\beta$ controls proliferation, cellular differentiation, and it acts as an antiproliferative factor in normal epithelial cells, and at early stages of oncogenesis. In the SMAD pathway, the TGF- $\beta$ dimers bind to a type- 2 receptor which recruits and phosphorylates a type- 1 receptor. The type- 1 receptor then recruits and phosphorylates a SMAD. This SMAD then binds to the common SMAD and forms a heterodimeric complex. This complex then enters the cell nucleus where it acts as a transcription factor for the various genes, including those to activate the MAP Kinase pathway, which triggers apoptosis. The TAK1-NLK-STAT3 pathway cascade participates in TGF- $\beta$-mediated mesoderm induction. Finally, MyD88 is a universal adaptor protein that is used by most of TLRs to activate the transcription factor NF- $\kappa \mathrm{B}$. These signals are closely associated with colitisassociated cancer formation. The abbreviations used in this figure are: Erk, extracellular signal-regulated kinases (=MAPK); HAD, histone deacetylase; IKK, I $\kappa$ B inhibitor; IRAK, IL-1 receptor associated kinase; JAK, Janus kinase; NLK, nemo-like kinase; MAPK, microtubuleassociated protein kinase; MEK, mitogen activated protein kinase; mTOR, mammalian target of rapamycin; MyD88, myeloid differentiation primary response gene 88; PI3K, phosphoinositide 3-kinase; STAT, signal transducer and activator of transcription; TAK, TGF- $\beta$ activated kinase; TBR, TGF- $\beta$ receptor; TCF, T cell factor; TGF, transforming growth factor; TLR, Toll-like receptor.

Th17 cells under a combination with immunosuppressive cytokines (e.g., TGF $\beta$ ) $[143,144]$. IL-6 expression is significantly increased in IBD and in murine models of colitis, and the blocking of IL-6 signaling significantly inhibits the severity of colitis in murine models [145-150]. A randomized pilot study of humanized anti-IL6R in active CD patients showed no beneficial effect in improvement with endoscopic and histologic examination, although an $80 \%$ improvement of clinical symptoms in patients who were treated with the $\mathrm{Ab}$ as compared to $31 \%$ improvement in placebo patients was noted [151].

IL-6 production is highly upregulated in colorectaltumor developing $\mathrm{APC}^{\text {min }}$ mice and animal models of CAC $[152,153]$. In human, increased serum levels of IL- 6 production have been identified in colorectal cancer patients [154]. IL- 6 expression is mainly regulated by NF- $\kappa \mathrm{B}$ activation, and IL- 6 acts on both CECs and immune cells $[155,156]$. Effects of IL- 6 are mediated mainly by transcription factor STAT3 activation in cancer cells, and STAT3-mediated cell activation further promotes cell-survival and cell-cycle progression of premalignant as well as cancer cells by inducing expression of antiapoptotic genes (e.g., Bcl2, Bcl-xL) and proliferation-associated genes (e.g., c-Myc, Cyclin D1) [157, 158]. Interestingly, inhibition of IL-6 signaling significantly reduced tumor development in AOM-induced CAC model, suggesting IL-6 trans-signaling plays a pivotal role in the development of colon cancer [159]. Li et al. recently demonstrated that expression of suppressor cytokine signaling 3 (SOCS3), which is the major negative regulator of STAT3, was significantly reduced in patients with UC-accompanied with colon cancer as compared to inactive UC or active UC, who had no colon cancer progression [160]. Therefore, IL-6 trans-signaling and STAT3 activation must be a potential and attractive therapeutic target for CAC progression.

5.1.3. IL-23/Il-12/IL-17. IL-23 is a heterodimeric cytokine consisting of two subunits, p40 (which is shared with IL12) and p19 (also called as IL-23 $\alpha$ subunit). IL-23 binds to a specific receptor, which is formed by IL-12RB1 and IL-23R. Both IL23 (p19/p40) and IL-12 (p35/p40) can activate the STAT4 transcription factor, and subsequently stimulate the production of IFN $\gamma$. In addition, IL-23, TGF $\beta$ and IL- 6 conjugationally stimulate naïve $\mathrm{CD} 4+\mathrm{T}$ cells to differentiate into Th17 cells, which produce the proinflammatory cytokine IL17 [161]. IL-23 plays an important role in the inflammatory response against infection, and the expression is increased in IBD $[162,163]$ and in colon cancer [164]. Shan et al. showed antitumor activity of IL-23 in a murine model of cancer, in which murine colon carcinoma cells retrovirally 


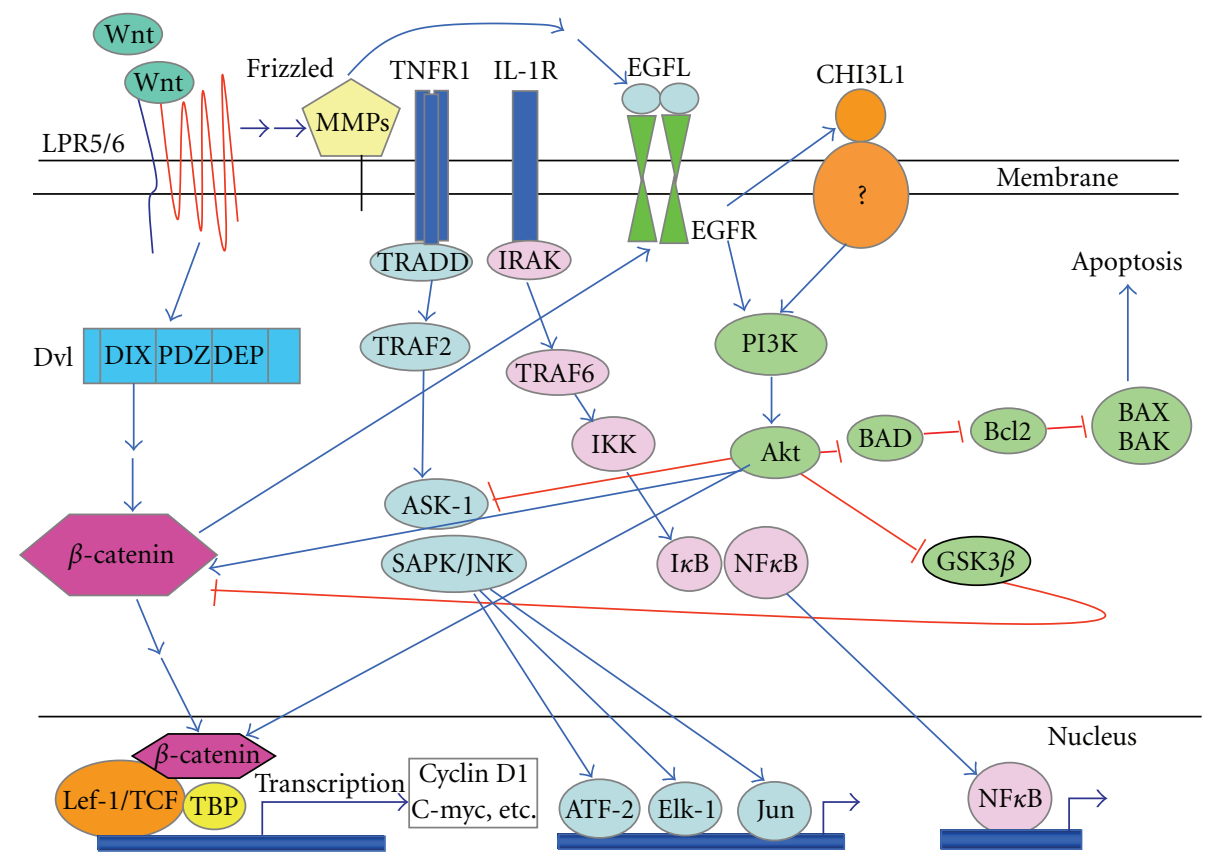

FIGURE 3: Wnt signaling plays central role in embryogenesis and human diseases including cancers. Wnt ligands to 7-transmembrane domain receptor Frizzled, which transactivates EGFR signaling by MMP-mediated release of soluble EGFR ligands. Activated EGFR transactivates $\beta$ catenin via receptor tyrosine kinase-PI3K/Akt pathway, and $\beta$-catenin also forms heterodimer with EGFR and further activate EGF pathway. Direct activation of EGFR utilizing EGF-family ligands induces CHI3L1 expression, which binds to a putative receptor on cell membrane and leads to PI3K-mediated phosphorylation of Akt followed by $\beta$-catenin transactivation. As shown in this figure, Wnt and EGFR pathways have been reported to closely interact in tumorigenesis by crosstalking and coactivating tumor progression. The activation of ASK1, following of TNF/TNFR1 and/or IL-1/IL-1R ligation, activates SAPK/JNK and MAPKp38 followed by increased production of MMPs and cytokines. NF- $\kappa \mathrm{B}$ signal is also activated by TNF and IL-1, which is highly involved in the development of chronic colitis as well as colitis-associated cancer formation. The abbreviations used in this figure are: ASK-1, apoptosis signal-regulating kinase 1; ATF-2, activating transcription factor 2; BAD, Bcl2-antagonist of cell death; Bcl2, B-cell lymphoma 2; CHI3L1, chitinase 3-like-1; EGF, epidermal growth factor; Elk-1, Ets like gene 1; GSK3 $\beta$, glycogen synthesis kinasse 3 beta, Lef-1/TCF, lymphoid enhancer-binding factor-1/Tcell factor; IKK, I $\kappa \mathrm{B}$ kinase; IRAK, IL-1 receptor associated factor; LPR5/6, lipoprotein-related receptor 5 and 6; PI3K, phosphoinositide 3-kinase; SAPK/JNK, stress-activated protein kinase/c-Jun NH2-terminal kinase; TBP, TATA-binding protein; TNFR1; Tumor necrosis factor receptor 1; TRADD, TNF receptor 1 -associated death domain; TRAF, TNF receptor associated factor.

transduced with mouse IL-23 gene were subcutaneously injected [165]. Interestingly, IL-23 secreted by tumor cells efficiently suppressed the growth of tumor and the survival of mice by enhancing the production of IFN $\gamma$, IL-12, and TNF $\alpha$ [165]. IL-23 and Th17 cytokines act coordinately to maintain the balance between tolerance and immunity in the gastrointestinal tract [166].

5.1.4. Cyclooxygenase (COX). COX is an important enzyme, which is responsible for forming prostanoids including prostaglandins. COX can convert arachidonic acid to prostaglandin $\mathrm{H}_{2}$, the precursor for prostaglandins, which act on a variety of cells and cause multiple actions including, but not limited to, muscular constriction and mediation of inflammation. So far, there are three COX isozymes: COX-1, COX-2, and COX-3 (a splice variant of COX-1). COX-1 is found in most mammalian cells constitutively, while COX-2 is undetectable in most normal cells but becomes abundant in macrophages and other cells under inflammatory conditions.

It has been reported that COX-2 is upregulated in various malignant cells and has a key role in inflammation- associated carcinogenesis. Oshima et al. first demonstrated the role of COX-2 in colorectal tumorigenesis in mice carrying a mutant $A p c$ gene encoding a product truncated at a 716 (Apc $\Delta 716)$, a mouse model of human familial adenomatous polyposis [167]. Another report also has suggested that intestinal epithelial cells upregulated Cox-2 expression in a TLR-4 and MyD88-dependent fashion. This signaling is required for optimal proliferation and protection against apoptosis in the injured intestine, while TLR4 may lower the threshold for carcinogenesis in an AOM/DSS-induced cancer model [168]. In the same model, endogenous administration of PGE2 treatment increased mucosal expression of COX-2, thus PGE2 involves in the TLR-4-mediated intestinal tumorigenesis [169].

COX inhibitors are compounds that can efficiently block the action of COX enzymes. Nonsteroidal anti-inflammatory drugs (NSAIDs) are widely utilized inhibitors for both of COX-1 and COX-2 enzymes. NSAIDs that selectively block the COX-2 enzyme but not COX-1 are called COX2 inhibitors that have less adverse effects. Selective COX2 inhibitors significantly reduced the number and size of intestinal polyps in Apc $\Delta 716$ mice $[167,170]$ and the 
occurrence of neoplasia in p53-deficient mice treated with DSS [171]. Celecoxib, another COX-2 inhibitor, prevents a wide variety of cancers including animal models of urinary bladder cancers [172], human breast cancer cells [173], human colon cancer cells [174], and human lung cancer [175], while clinical trials participants taking celecoxib had a significant increase in their blood pressure, which may have affected their heart disease risk $[176,177]$.

Besides the NSAIDs, salicylates, such as aspirin (acetylsalicylic acid), methyl salicylate and sodium salicylate, are widely used as drugs for their analgesic, anti-inflammatory, and antipyretic effects. Salicylates, including aspirin, inhibit prostaglandin synthesis, and aspirin is able to irreversibly inactivate both COX-1 and COX-2. More recently, it has been reported that regular intake of aspirin has been associated with a decreased incidence of colon cancer [178]. Some double-blind randomized placebo-controlled clinical trials indicate that daily consumption of aspirin $(75-80 \mathrm{mg}$ ) can lead to a $40 \%-50 \%$ decrease in the risk of developing colon cancer $[179,180]$. The aspirin-mediated antitumor effect is also supported by animal models, including 1,2dimethylhydrazine-induced colon cancer model in SpragueDawley rats [181], AOM-induced colon carcinogenesis in F344 rats [182], and intestinal adenomas model in $\mathrm{APC}^{\mathrm{min} /+}$ mice [183]. In addition, antineoplastic effect can be achieved by eating salicylic acid-rich foods (e.g., a wide range of fruit, vegetables, herbs, and spices) at concentrations as low as $100 \mathrm{nM} / \mathrm{mL}$ [184].

\subsection{Regulatory Factors}

5.2.1. IL-10. IL-10 (also known as human cytokine synthesis inhibitory factor: CSIF) is a key anti-inflammatory cytokine produced primarily by monocytes, $\mathrm{T}$ cells and $\mathrm{B}$ cells. IL10 can block NF- $\kappa \mathrm{B}$ activity, and also regulates the JAKStat signaling pathway [185]. IL-10 interacts with IL-10 receptor $\alpha$ subunit (IL-10RA) and inhibits the synthesis of proinflammatory cytokines such as IL-6 $[18,186]$. IL-10 KO mice develop spontaneous colitis, which is similar to human IBD, in particular CD [187]. These mice also develop colitis-associated cancer, which is associated with the overproduction of Th1 cytokine [61]. AOM and DSS treatment promotes inflammation-mediated colonic tumor growth in IL-10 KO mice [67]. Furthermore, Helicobacter hepaticus infection promotes AOM-induced tumorigenesis as compared to AOM treatment alone in IL-10 KO mice [68]. We have summarized chronic colitis and CAC development in IL-10 KO in Sections 2 and 3 in this review.

5.2.2. Transforming Growth Factor (TGF)- $\beta$. TGF- $\beta$ has an antiproliferative effect in normal epithelial cells as well as early stage of oncogenesis [188]. TGF $\beta$ has three protein precursors, the so-called TGF- $\beta 1,-\beta 2$, and $-\beta 3$, and each have an N-terminal short (20-30 amino acids) signal peptide. The C-terminal region becomes the mature TGF- $\beta$ protein, which makes a homodimer to produce an active molecule [189]. There are three TGF- $\beta$ receptors: types I and II have a high affinity for TGF- $\beta 1$, and type III has a high affinity for both TGF- $\beta 1$, and $-\beta 2$. In most of cases, an activated TGF- $\beta$ ligand will initiate the TGF- $\beta$ signaling by binding these receptors. TGF- $\beta$ can induce FoxP3 in human CD4+ CD25+ $\mathrm{T}$ cells and regulate the development of $\mathrm{CD} 25+$ regulatory $\mathrm{T}$ cells [190]. In normal cells, TGF- $\beta$ blocks cell cycles at the G1 stage and stops proliferation and differentiation of cells and promotes apoptosis [191]. However, once an epithelial cell has been transformed into an adenocarcinoma, parts of TGF- $\beta$ signaling are mutated, and subsequently TGF- $\beta$ promotes tumor growth, migration, invasion, and metastasis at an advanced stage of CAC [192]. Recently, Becker's group elegantly demonstrated that TGF- $\beta$ receptor II-deficient mice developed an increased number of tumors as compared to WT mice. In contrast, TGF- $\beta$ transgenic mice showed significantly less number of tumors as compared to WT. The authors concluded that TGF- $\beta$ signaling in infiltrating T cells suppresses colon cancer progression by inhibiting IL-6 transsignaling in tumor cells [159]. Overall, TGF- $\beta$ seems to have a protective effect on chronic colitis and CAC development, at least in early stages [193].

Insulin-Like Growth Factor (IGF). IGFs are polypeptides, which show a high sequential homology to insulin. IGFs generate a complex system with two ligands (IGF-1 and IGF-2), two receptors (IGF1R and IGF2R), a family of six IGF-binding proteins (IGFBP 1-6), and associated IGFBP degrading enzymes $[194,195]$. IGF1R activation leads to autophosphorylation of receptor and activation of signaling cascades including the GRB2/Ras/ERK and IRS-1/PI3K/AKT pathways [196]. Of note, IGF-2 is overexpressed in many solid tumors including colon cancer [197], and also loss of imprinting (LOI), an epigenetic alteration, of IGF-2 gene (IGF2) was discovered in many types of cancer including ovarian, lung, liver, and colon [198]. Approximately 10\% of the population shows LOI of IGF2, and it seems to be associated with a personal and/or familial history of colorectal neoplasia since the variant showed a 5-fold increased frequency of colon cancer $[199,200]$. Kaneda et al. reported that LOI and $\mathrm{APC}^{\mathrm{min}}$ double heterozygous mice have an enhanced sensitivity to IGF-2 signaling, and AOMtreatment in those mice showed a $60 \%$ increased number of premalignant aberrant crypt foci formation as compared to LOI(-) littermates [201]. These results strongly suggest that epigenetic alterations in IGF2 in normal cells may affect cancer risk by altering the balance of differentiated and undifferentiated cells [201].

As described above, IGFs and IGFRs have been highly implicated in cancer pathophysiology. It has been reported by some groups that IGF1R inhibition by administrating an antagonistic monoclonal antibody against IGF1R (designated EM164) [202] or selective kinase inhibitor [203] (designated NVP-ADW742) showed antiproliferative and/or proapoptotic effects in solid tumors, suggesting that selective IGF1R inhibitors should be one of the useful therapeutic strategies in treating cancers.

Endothelial Growth Factor (EGF). EGF is a low molecular weight $(6 \mathrm{KDa})$ polypeptide, which plays a pivotal role in 
cellular proliferation, differentiation, cell growth, and cell survival by binding with high affinity to its receptor EGFR on the cell surface and subsequently stimulates the intrinsic protein-tyrosine activity of EGFR [204-206]. On the basis of several clinical trials, EGF appears promising for the treatment of IBD. An approximate $80 \%$ remission rate has been demonstrated in left sided UC patients with daily EGF enemas for 2 weeks as compared to $8 \%$ in placebo group $(P<$.001) [207]. Rabamipide, an amino acid analogue of 2-(1H)-quinolinone, efficiently upregulates EGF and EGFR expression. A significant improvement was observed in the clinical and endoscopic findings with twice daily Rabamipide enemas, which were given to patients with UC proctitis for one month [110]. There is a big concern, however, that systemic use of EGF might have potent mitogenic effect by increasing tumor development and/or progression in APC Min mice [208]. EGFR signaling seems to be required for early stages of colonic carcinogenesis by upregulating cyclin D1 and Cox-2 expressions in microadenomas in AOMinduced cancer model [209]. EGF can form a complex with $\beta$-catenin, possibly through receptor tyrosine kinasePI3K/Akt pathway, and further activate Wnt signaling pathway [210]. As shown in Figure 3, cross-communication between Wnt- and EGFR-signaling pathways allows the integration of the diversity of stimuli in CECs and promotes tumor progression [210]. Furthermore, EGFR signaling augments the expression of epithelial CHI3L1 [211], which further promotes tumor angiogenesis and migration [212]. EGF signaling also upregulates the proliferation of aberrant crypt foci, which is the precursor to colon cancer [213]. In summary, EGF may be a useful therapeutic reagent for treating severe UC, but at the same time, it has a subsequent risk of malignant change in the early stage of colon cancer.

5.2.3. Calcium. Calcium is an essential dietary mineral, which is commonly included in milk products and dark green vegetables. It has been reported that a calcium enriched diet significantly reduces the number of total aberrant crypt foci in AOM-treated mice or rats [214]. Other reports utilizing animal models also support findings of calcium's ability to inhibit colorectal cancer development $[215,216]$. According to a report of the American Cancer Society's Cancer Prevention Study II Nutrition Cohort, which recruited more than 120,000 examinees, men and women who had the highest intakes (approximately $1200 \mathrm{mg}$ per day) of calcium showed a modestly reduced risk of colorectal cancer compared with those who had the lowest intakes of calcium [217]. Many other studies also report that individuals who had a modest to high calcium intake reduced their risk of cancer [218-220]. The exact mechanistic of action of calcium is still unclear, but it binds to bile acids and fatty acids in the gastrointestinal tract to form insoluble complexes (calcium soaps). In addition, calcium may suppress cell proliferation in the lining of the colon or cause proliferating colon cells to undergo differentiation [221].

5.3. Chemokines. Chemokines are small chemotactic cytokines, and classified as 4 different types: CC-, CXC-, C-, and $\mathrm{CX} 3 \mathrm{C}$-chemokines. Chemokines bind to chemokine receptors, which are $\mathrm{G}$ protein-coupled receptors, and they are divided into four families: CXCR (bind CXC chemokines), CCR (bind CC chemokines), CX3CR1 (binds to CX3C), and XCR1 (binds to XC chemokines) [222]. Some chemokines have proinflammatory effects and efficiently promote migration of hematopoietic and nonhematopoietic cells to the site of infection or inflammation. In contrast, other chemokines keep tissue homeostasis during the normal process of tissue development. TNF $\alpha$ induces expression of several chemokines in colonic mucosal cells during the development of IBD [223]. TIR8 (also called as SIGIRR, a member of IL-1/TLR family) deficient mice cause severe colitis with cancer formation after AOM/DSS-induced colitis, and these mice showed significantly increased production of KC/CXC, MCP-1/CCL2, and MIP1 $\alpha /$ CCL3 chemokines by tumor cells [224]. These chemokines enhance leukocyte infiltration and tumor growth/migration. In particular, CXC and MCP-1 chemokines are known for their effects in enhancing angiogenesis in colon cancer $[225,226]$. Popivanova et al. also reported that MCP-1/CCL2 is a crucial mediator of colon cancer development since CCR2 (a specific receptor for MCP-1/CCL2) KO mice showed a milder form of colitis with less macrophage infiltration and a lower incidence of tumors with attenuated COX-2 expression in the AOM challenged model [134]. In contrast, MCP-1/CCL2-antagonist-treated mice showed reduced tumor incidence and size in the same animal model. These results strongly suggest that MCP-1/CCL2 may be a potential target in the treatment of colorectal carcinoma associated with chronic inflammation. Furthermore, D6 (a promiscuous decoy and receptor that scavenges inflammatory CC chemokines) plays a nonredundant role in suppressing inflammatory immune responses in various organs including lungs and skin [227]. D6 KO mice were more susceptible to chemically induced colitis, as compared to WT mice, and failed to recover from the colitis. They also exhibited a higher level of proinflammatory cytokine productions and increased number of tumor development in the distal part of colon [227]. In summary, CC-chemokines and their receptors are novel players in tumor promotion and progression during the course of chronic colitis.

5.4. Mammalian Chitinases. Chitin, a polymer of $\beta-1,4-\mathrm{N}-$ acetyl-glucosamine, is produced by various living organisms including insects, fungi, crustaceans, and many other organisms except mammals [228]. Chitin can be degraded by chitinases (EC 3.2.1.14) that belong to members of the glycohydrolase family 18 , in which bacterial as well as plant chitinases are included [229]. Chitinases have been generally considered to lack in mammalian bodies due to the absence of chitin. However, recent studies have identified many chitinases including CHI3L1 [230], acidic mammalian chitinase [231], chitotriosidase [232], and Ym-1 [233] in mammals, and the expression of these chitinases is highly upregulated during the development of chronic inflammation conditions [25].

Serum levels of CHI3L1 are significantly elevated in patients with IBD [234] as well as those with colorectal 
cancer [235], and the expression is positively associated with bad prognosis of these patients [236, 237]. CHI3L1 plays an important role in protecting cancer cells from undergoing apoptosis and also effects cellular invasion by strongly binding with heparin, collagens, and hyaluronic acid, all of these are important constituents of extracellular matrix $[238,239]$. Recently, it has been reported that normal human bronchial epithelial cells express CHI3L1 under mechanical stress, which is driven by an EGFR and extracellular signalregulated kinases (ERK)-1/2 signaling pathways. This result strongly suggests that direct activation of EGFR with ERK family ligands such as EGF and heparin-binding (HB) EGF induces CHI3L1 expression in epithelial cells [240]. Therefore, growth-stimulating effects of epithelial CHI3L1 in response to inflammatory or stressful stimuli seems to be a critical and physiological function in remodeling and maintaining the basic architecture of epithelium; however, overproduction of CHI3L1 from the epithelium must be a cue for further prolonged inflammation and for developing inflammation-associated carcinogenesis, ironically. Currently, exact biological function of CHI3L1 as well as other chitinases in CAC is still largely unknown. Further studies will help clarify the critical role of mammalian chitinases in chronic inflammation and the following carcinogenic change in epithelial cells, which will provide a rationale for the development of novel and new type of immunotherapy for improving the lives of patients with inflammation-associated carcinogenesis.

\section{Conclusions}

It has been strongly anticipated to improve the clinical course of IBD patients not only by creating new diagnostic and therapeutic approaches but also by preventing inflammationassociated cancer formation. Currently, a variety of genetically engineered or chemically induced animal models of CAC are available and are very useful for further analysis of the exact mechanisms underlying the pathogenesis of CAC. Through the animal models, we have learned that a limited number of inflammatory cytokines, chemokines, and growth factors play crucial roles in CAC development. Thus, effective and targeted anti-inflammatory therapies without adverse effects are warranted in order to prevent the development of CAC in IBD patients, and the animal models would help us with the invention of anti-inflammatory therapies by testing therapeutic strategies and reagents in preclinical settings.

\section{Abbreviations}

AOM: Azoxymethane

APC: Adenomatous polyposis coli

APC/C: Anaphase-promoting complex

BUB: Budding uninhibited by benzimidazoles

CAC: Colitis-associated cancer

CCL: Chemokine (C-C motif) ligand

CCR: Chemokine (C-C motif) receptor

CD: Crohn's disease

CECs: Colonic epithelial cells

$\begin{array}{ll}\text { CHI3L1: } & \text { Chitinase 3-like-1 (YKL-40) } \\ \text { COX-2: } & \text { Cyclooxygenase-2 } \\ \text { CTT: } & \text { Cotton top tamarins } \\ \text { DMH: } & \text { 1,2-dimethylhydrazine } \\ \text { EGF: } & \text { Epidermal growth factor } \\ \text { ERK: } & \text { Extracellular signal regulated kinases } \\ \text { FAP: } & \text { Familial adenomatous polyposis } \\ \text { HNPCC: } & \text { Hereditary nonpolyposis colorectal cancer } \\ \text { IBD: } & \text { Inflammatory bowel disease } \\ \text { IFN: } & \text { Interferone } \\ \text { IGF: } & \text { Insulin-like growth factor } \\ \text { iNOS: } & \text { Inducible nitric oxide synthesis } \\ \text { KO: } & \text { Knockout } \\ \text { MAD: } & \text { Mitotic arrest-deficient } \\ \text { MAM: } & \text { Methyl azoxy methane } \\ \text { MCP: } & \text { Monocyte-chemoattractant proteins } \\ \text { MIP: } & \text { Macrophage inflammatory proteins } \\ \text { MSI: } & \text { Microsatellite instability } \\ \text { NSAIDs: } & \text { Nonsteroidal anti-inflammatory drugs } \\ \text { sPLA: } & \text { Secretory phospholipase } \\ \text { TGF: } & \text { Transforming growth factor } \\ \text { TLRs: } & \text { Toll-like receptors } \\ \text { TNFRs: } & \text { Tumor necrosis factor receptors } \\ \text { UC: } & \text { Ulcerative colitis } \\ \text { WT: } & \text { Wild type. }\end{array}$

\section{Acknowledgments}

The authors are grateful to Dr. Atsushi Mizoguchi for his helpful discussion and advice. The authors would like to thank Mr. Terry Danford Lott and Ms. Cindy W. Lau for their excellent assistance in preparing this paper. This work has been supported by National Institute of Health (DK 80070, DK74454, DK64289, and DK43351), and grants from the Eli and Edythe L. Broad Medical Foundation and American Gastroenterological Association Foundation to E. Mizoguchi. M. Kanneganti is a recipient of a Student Research Fellowship Award from the Crohn's and Colitis Foundation of America Inc. in 2010.

\section{References}

[1] B. Crohn and H. Rosenberg, "The sigmoidoscopic picture of chronic ulcerative colitis (non-specific)," American Journal of the Medical Sciences, vol. 170, pp. 220-228, 1925.

[2] J. A. Eaden, K. R. Abrams, and J. F. Mayberry, "The risk of colorectal cancer in ulcerative colitis: a meta-analysis," Gut, vol. 48, no. 4, pp. 526-535, 2001.

[3] D. Kornfeld, A. Ekbom, and T. Ihre, "Is there an excess risk for colorectal cancer in patients with ulcerative colitis and concomitant primary sclerosing cholangitis? A population based study," Gut, vol. 41, no. 4, pp. 522-525, 1997.

[4] A. Vera, B. K. Gunson, V. Ussatoff et al., "Colorectal cancer in patients with inflammatory bowel disease after liver transplantation for primary sclerosing cholangitis," Transplantation, vol. 75, no. 12, pp. 1983-1988, 2003.

[5] L. Lakatos, G. Mester, Z. Erdelyi et al., "Risk factors for ulcerative colitis-associated colorectal cancer in a Hungarian cohort of patients with ulcerative colitis: results of a 
population-based study," Inflammatory Bowel Diseases, vol. 12, no. 3, pp. 205-211, 2006.

[6] R. F. Willenbucher, S. J. Zelman, L. D. Ferrell, D. H. Moore 2nd, and F. M. Waldman, "Chromosomal alterations in ulcerative colitis-related neoplastic progression," Gastroenterology, vol. 113, no. 3, pp. 791-801, 1997.

[7] T. Byers, B. Levin, D. Rothenberger, G. D. Dodd, and R. A. Smith, "American Cancer Society guidelines for screening and surveillance for early detection of colorectal polyps and cancer: update 1997," Ca-A Cancer Journal for Clinicians, vol. 47, no. 3, pp. 154-160, 1997.

[8] M. N. Kulaylat and M. T. Dayton, "Ulcerative colitis and cancer," Journal of Surgical Oncology, vol. 101, no. 8, pp. 706712, 2010.

[9] D. K. Podolsky, "Mucosal immunity and inflammation V. Innate mechanisms of mucosal defense and repair: the best offense is a good defense," American Journal of PhysiologyGastrointestinal and Liver Physiology, vol. 277, no. 3, pp. G495-G499, 1999.

[10] L. V. Hooper, M. H. Wong, A. Thelin, L. Hansson, P. G. Falk, and J. I. Gordon, "Molecular analysis of commensal hostmicrobial relationships in the intestine," Science, vol. 291, no. 5505, pp. 881-884, 2001.

[11] C. L. Wilson, A. J. Ouellette, D. P. Satchell et al., "Regulation of intestinal $\alpha$-defensin activation by the metalloproteinase matrilysin in innate host defense," Science, vol. 286, no. 5437, pp. 113-117, 1999.

[12] L. M. Higgins, G. Frankel, I. Connerton, N. S. Gonçalves, G. Dougan, and T. T. MacDonald, "Role of bacterial intimin in colonic hyperplasia and inflammation," Science, vol. 285, no. 5427, pp. 588-591, 1999.

[13] W. E. W. Roediger and W. Babidge, "Human colonocyte detoxification," Gut, vol. 41, no. 6, pp. 731-734, 1997.

[14] E. Mizoguchi, R. J. Xavier, H. C. Reinecker et al., "Colonic epithelial functional phenotype varies with type and phase of experimental colitis," Gastroenterology, vol. 125, no. 1, pp. 148-161, 2003.

[15] M. D. Levitt, J. Furne, J. Springfield, F. Suarez, and E. DeMaster, "Detoxification of hydrogen sulfide and methanethiol in the cecal mucosa," Journal of Clinical Investigation, vol. 104, no. 8, pp. 1107-1114, 1999.

[16] E. Mizoguchi, A. Mizoguchi, H. Takedatsu et al., "Role of tumor necrosis factor receptor 2 (TNFR2) in colonic epithelial hyperplasia and chronic intestinal inflammation in mice," Gastroenterology, vol. 122, no. 1, pp. 134-144, 2002.

[17] E. Cario, I. M. Rosenberg, S. L. Brandwein, P. L. Beck, H. C. Reinecker, and D. K. Podolsky, "Lipopolysaccharide activates distinct signaling pathways in intestinal epithelial cell lines expressing Toll-like receptors," Journal of Immunology, vol. 164, no. 2, pp. 966-972, 2000.

[18] S. Danese and A. Mantovani, "Inflammatory bowel disease and intestinal cancer: a paradigm of the Yin-Yang interplay between inflammation and cancer," Oncogene, vol. 29, no. 23, pp. 3313-3323, 2010.

[19] P. Szlosarek, K. A. Charles, and F. R. Balkwill, "Tumour necrosis factor- $\alpha$ as a tumour promoter," European Journal of Cancer, vol. 42, no. 6, pp. 745-750, 2006.

[20] S. A. Jones, "Directing transition from innate to acquired immunity: defining a role for IL-6," Journal of Immunology, vol. 175, no. 6, pp. 3463-3468, 2005.

[21] F. R. Greten, L. Eckmann, T. F. Greten et al., "IKK $\beta$ links inflammation and tumorigenesis in a mouse model of colitisassociated cancer," Cell, vol. 118, no. 3, pp. 285-296, 2004.
[22] H. C. Reinecker, E. Y. Loh, D. J. Ringler, A. Mehta, J. L. Rombeau, and R. P. MacDermott, "Monocytechemoattractant protein 1 gene expression in intestinal epithelial cells and inflammatory bowel disease mucosa," Gastroenterology, vol. 108, no. 1, pp. 40-50, 1995.

[23] L. Mazzucchelli, C. Hauser, K. Zgraggen et al., "Differential in situ expression of the genes encoding the chemokines MCP1 and RANTES in human inflammatory bowel disease," Journal of Pathology, vol. 178, no. 2, pp. 201-206, 1996.

[24] B. K. Popivanova, K. Kitamura, Y. Wu et al., "Blocking TNF$\alpha$ in mice reduces colorectal carcinogenesis associated with chronic colitis," Journal of Clinical Investigation, vol. 118, no. 2, pp. 560-570, 2008.

[25] K. Eurich, M. Segawa, S. Toei-Shimizu, and E. Mizoguchi, "Potential role of Chitinase 3-like-1 in inflammationassociated carcinogenic changes of epithelial cells," World Journal of Gastroenterology, vol. 15, no. 42, pp. 5249-5259, 2009.

[26] M. Segawa, J. Zhang, K. Eurich et al., "M1936 Chitinase 3like-1 enhances inflammation-associated tumorigenesis by activating the $\beta$-catenin/Wnt signaling pathway of CECs," Gastroenterology, vol. 138, no. 5, Supplement 1, p. S-443, 2010.

[27] C. R. Boland, S. N. Thibodeau, S. R. Hamilton et al., "A National Cancer Institute workshop on microsatellite instability for cancer detection and familial predisposition: development of international criteria for the determination of microsatellite instability in colorectal cancer," Cancer Research, vol. 58, no. 22, pp. 5248-5257, 1998.

[28] S. H. Itzkowitz and X. Yio, "Inflammation and cancerIV. Colorectal cancer in inflammatory bowel disease: the role of inflammation," American Journal of PhysiologyGastrointestinal and Liver Physiology, vol. 287, no. 1, pp. G7G17, 2004.

[29] A. Goel, C. N. Arnold, D. Niedzwiecki et al., "Characterization of sporadic colon cancer by patterns of genomic instability," Cancer Research, vol. 63, no. 7, pp. 1608-1614, 2003.

[30] A. Rowan, S. Halford, M. Gaasenbeek et al., "Refining molecular analysis in the pathways of colorectal carcinogenesis," Clinical Gastroenterology and Hepatology, vol. 3, no. 11, pp. 1115-1123, 2005.

[31] J. C. Weber, N. Meyer, E. Pencreach et al., "Allelotyping analyses of synchronous primary and metastasis CIN colon cancers identified different subtypes," International Journal of Cancer, vol. 120, no. 3, pp. 524-532, 2007.

[32] T. Boveri, Zur Frage der Entstehung Maligner Tumoren, Gustav Fischer, Jena, Germany, 1914.

[33] F. Herzog, I. Primorac, P. Dube et al., "Structure of the anaphase-promoting complex/cyclosome interacting with a mitotic checkpoint complex," Science, vol. 323, no. 5920, pp. 1477-1481, 2009.

[34] D. P. Cahill, C. Lengauer, J. Yu et al., "Mutations of mitotic checkpoint genes in human cancers," Nature, vol. 392, no. 6673, pp. 300-303, 1998.

[35] Z. Wang, J. M. Cummins, D. Shen et al., "Three classes of genes mutated in colorectal cancers with chromosomal instability," Cancer Research, vol. 64, no. 9, pp. 2998-3001, 2004.

[36] N. J. Ganem, S. A. Godinho, and D. Pellman, "A mechanism linking extra centrosomes to chromosomal instability," Nature, vol. 460, no. 7252, pp. 278-282, 2009.

[37] H. Katayama, T. Ota, F. Jisaki et al., "Mitotic kinase expression and colorectal cancer progression," Journal of the 
National Cancer Institute, vol. 91, no. 13, pp. 1160-1162, 1999.

[38] L. Macůrek, A. Lindqvist, D. Lim et al., "Polo-like kinase1 is activated by aurora A to promote checkpoint recovery," Nature, vol. 455, no. 7209, pp. 119-123, 2008.

[39] T. Takahashi, B. Sano, T. Nagata et al., "Polo-like kinase 1 (PLK1) is overexpressed in primary colorectal cancers," Cancer Science, vol. 94, no. 2, pp. 148-152, 2003.

[40] R. Chen, P. S. Rabinovitch, D. A. Crispin, M. J. Emond, M. P. Bronner, and T. A. Brentnall, "The initiation of colon cancer in a chronic inflammatory setting," Carcinogenesis, vol. 26, no. 9, pp. 1513-1519, 2005.

[41] K. J. Sohn, S. A. Shah, S. Reid et al., "Molecular genetics of ulcerative colitis-associated colon cancer in the interleukin 2and $\beta$-microgiobulin-deficient mouse," Cancer Research, vol. 61, no. 18, pp. 6912-6917, 2001.

[42] R. L. Shattuck-Brandt, G. W. Varilek, A. Radhika, F. Yang, M. K. Washington, and R. N. DuBois, "Cyclooxygenase 2 expression is increased in the stroma of colon carcinomas from IL-10(-/-) mice," Gastroenterology, vol. 118, no. 2, pp. 337-345, 2000.

[43] S. E. Erdman, T. Poutahidis, M. Tomczak et al., "CD4+ $\mathrm{CD} 25+$ regulatory $\mathrm{T}$ lymphocytes inhibit microbially induced colon cancer in Rag2-deficient mice," American Journal of Pathology, vol. 162, no. 2, pp. 691-702, 2003.

[44] S. Kado, K. Uchida, H. Funabashi et al., "Intestinal microflora are necessary for development of spontaneous adenocarcinoma of the large intestine in T-cell receptor $\beta$ chain and p53 double-knockout mice," Cancer Research, vol. 61, no. 6, pp. 2395-2398, 2001.

[45] F. F. Chu, R. S. Esworthy, P. G. Chu et al., "Bacteria-induced intestinal cancer in mice with disrupted Gpx1 and Gpx2 genes," Cancer Research, vol. 64, no. 3, pp. 962-968, 2004.

[46] U. Rudolph, M. J. Finegold, S. S. Rich et al., "Ulcerative colitis and adenocarcinoma of the colon in $\mathrm{G} \alpha(\mathrm{i} 2)$-deficient mice," Nature Genetics, vol. 10, no. 2, pp. 143-150, 1995.

[47] A. H. Reitmair, M. Redston, J. C. Cai et al., "Spontaneous intestinal carcinomas and skin neoplasms in Msh2-deficient mice," Cancer Research, vol. 56, no. 16, pp. 3842-3849, 1996.

[48] W. Edelmann, A. Umar, K. Yang et al., "The DNA mismatch repair genes Msh3 and Msh6 cooperate in intestinal tumor suppression," Cancer Research, vol. 60, no. 4, pp. 803-807, 2000.

[49] W. Edelmann, K. Yang, M. Kuraguchi et al., "Tumorigenesis in Mlh1 and Mlh1/Apc1638N mutant mice," Cancer Research, vol. 59, no. 6, pp. 1301-1307, 1999.

[50] P.-C. Chen, S. Dudley, W. Hagen et al., "Contributions by MutL homologues Mlh3 and Pms2 to DNA mismatch repair and tumor suppression in the mouse," Cancer Research, vol. 65, no. 19, pp. 8662-8670, 2005.

[51] D. P. Lin, Y. Wang, S. J. Scherer et al., "An Msh2 point mutation uncouples DNA mismatch repair and apoptosis," Cancer Research, vol. 64, no. 2, pp. 517-522, 2004.

[52] E. Avdievich, C. Reiss, S. J. Scherer et al., "Distinct effects of the recurrent Mlh1 mutation on MMR functions, cancer, and meiosis," Proceedings of the National Academy of Sciences of the United States of America, vol. 105, no. 11, pp. 4247-4252, 2008.

[53] A. R. Moser, C. Luongo, K. A. Gould, M. K. McNeley, A. R. Shoemaker, and W. F. Dove, "ApcMin: a mouse model for intestinal and mammary tumorigenesis," European Journal of Cancer, vol. 31, no. 7-8, pp. 1061-1064, 1995.
[54] E. Half, D. Bercovich, and P. Rozen, "Familial adenomatous polyposis," Orphanet Journal of Rare Diseases, vol. 4, no. 1, article 22, 2009.

[55] A. E. McCart, N. K. Vickaryous, and A. Silver, "Apc mice: models, modifiers and mutants," Pathology Research and Practice, vol. 204, no. 7, pp. 479-490, 2008.

[56] S. R. Ritland and S. J. Gendler, "Chemoprevention of intestinal adenomas in the $\mathrm{Apc}^{\mathrm{Min}}$ mouse by piroxicam: kinetics, strain effects and resistance to chemosuppression," Carcinogenesis, vol. 20, no. 1, pp. 51-58, 1999.

[57] R. Fodde and R. Smits, "Disease model: familial adenomatous polyposis," Trends in Molecular Medicine, vol. 7, no. 8, pp. 369-373, 2001.

[58] A. R. Moser, L. F. Hegge, and R. D. Cardiff, "Genetic background affects susceptibility to mammary hyperplasias and carcinomas in Apc $\mathrm{Ain}^{\mathrm{Min}}+$ mice," Cancer Research, vol. 61, no. 8, pp. 3480-3485, 2001.

[59] A. R. Moser, A. R. Shoemaker, C. S. Connelly et al., "Homozygosity for the Min allele of Apc results in disruption of mouse development prior to gastrulation," Developmental Dynamics, vol. 203, no. 4, pp. 422-433, 1995.

[60] P. Alberici and R. Fodde, "The role of the APC tumor suppressor in chromosomal instability," in Genome and Disease, J. N. Volff, Ed., vol. 1 of Genome Dynamics, pp. 149170, Karger, Basel, Switzerland, 2006.

[61] D. J. Berg, N. Davidson, R. Kühn et al., "Enterocolitis and colon cancer in interleukin-10-deficient mice are associated with aberrant cytokine production and $\mathrm{CD}^{+}$Th1-like responses," Journal of Clinical Investigation, vol. 98, no. 4, pp. 1010-1020, 1996.

[62] S. Sturlan, G. Oberhuber, B. G. Beinhauer et al., "Interleukin10-deficient mice and inflammatory bowel disease associated cancer development," Carcinogenesis, vol. 22, no. 4, pp. 665671, 2001.

[63] S. Kraus and N. Arber, "Inflammation and colorectal cancer," Current Opinion in Pharmacology, vol. 9, no. 4, pp. 405-410, 2009.

[64] P. L. Beatty, S. E. Plevy, A. R. Sepulveda, and O. J. Finn, "Cutting edge: transgenic expression of human MUC1 in IL-10 mice accelerates inflammatory bowel disease and progression to colon cancer," Journal of Immunology, vol. 179, no. 2, pp. 735-739, 2007.

[65] D. M. Rennick and M. M. Fort, "Lessons from genetically engineered animal models. XII. IL-10-deficient (IL-10(-/) mice and intestinal inflammation," American Journal of Physiology-Gastrointestinal and Liver Physiology, vol. 278, no. 6, pp. G829-G833, 2000.

[66] M. Chichlowski, J. M. Sharp, D. A. Vanderford, M. H. Myles, and L. P. Hale, "Helicobacter typhlonius and Helicobacter rodentium differentially affect the severity of colon inflammation and inflammation-associated neoplasia in IL10deficient mice," Comparative Medicine, vol. 58, no. 6, pp. 534-541, 2008.

[67] R. Glauben, A. Batra, T. Stroh et al., "Histone deacetylases: novel targets for prevention of colitis-associated cancer in mice," Gut, vol. 57, no. 5, pp. 613-622, 2008.

[68] C. M. Nagamine, A. B. Rogers, J. G. Fox, and D. B. Schauer, "Helicobacter hepaticus promotes azoxymethane-initiated colon tumorigenesis in BALB/c-IL10-deficient mice," International Journal of Cancer, vol. 122, no. 4, pp. 832-838, 2008.

[69] S. R. Neves, P. T. Ram, and R. Iyengar, "G protein pathways," Science, vol. 296, no. 5573, pp. 1636-1639, 2002. 
[70] U. Rudolphs, M. J. Finegold, S. S. Rich et al., "G(i2) $\alpha$ protein deficiency: a model for inflammatory bowel disease," Journal of Clinical Immunology, vol. 15, no. 6, pp. 101S-105S, 1995.

[71] F. H. Gordon, C. W. Y. Lai, M. I. Hamilton et al., "A randomized placebo-controlled trial of a humanized monoclonal antibody to $\alpha 4$ integrin in active Crohn's disease," Gastroenterology, vol. 121, no. 2, pp. 268-274, 2001.

[72] F. H. Gordon, M. I. Hamilton, S. Donoghue et al., "A pilot study of treatment of active ulcerative colitis with natalizumab, a humanized monoclonal antibody to alpha-4 integrin," Alimentary Pharmacology and Therapeutics, vol. 16, no. 4, pp. 699-705, 2002.

[73] P. E. Hesterberg, D. Winsor-Hines, M. J. Briskin et al., "Rapid resolution of chronic colitis in the cotton-top tamarin with an antibody to a gut-homing integrin alpha 4 beta," Gastroenterology, vol. 121, pp. 268-274, 2001.

[74] D. K. Podolsky, R. Lobb, N. King et al., "Attenuation of colitis in the cotton-top tamarin by anti- $\alpha 4$ integrin monoclonal antibody," Journal of Clinical Investigation, vol. 92, no. 1, pp. 372-380, 1993.

[75] M. Bjursten, P. W. Bland, R. Willén, and E. H. Hörnquist, "Long-term treatment with anti- $\alpha 4$ integrin antibodies aggravates colitis in G $\alpha \mathrm{i} 2$-deficient mice," European Journal of Immunology, vol. 35, no. 8, pp. 2274-2283, 2005.

[76] N. K. Clapp, M. L. Henke, C. C. Lushbaugh, G. L. Humason, and B. L. Gangaware, "Effect of various biological factors on spontaneous marmoset and tamarin colitis. A retrospective histopathologic study," Digestive Diseases and Sciences, vol. 33, no. 8, pp. 1013-1019, 1988.

[77] K. E. Saunders, Z. Shen, F. E. Dewhirst, B. J. Paster, C. A. Dangler, and J. G. Fox, "Novel intestinal Helicobacter species isolated from cotton-top tamarins (Saguinus oedipus) with chronic colitis," Journal of Clinical Microbiology, vol. 37, no. 1, pp. 146-151, 1999.

[78] E. R. Bertone, E. L. Giovannucci, N. W. King, A. J. Petto, and L. D. Johnson, "Family history as a risk factor for ulcerative colitis-associated colon cancer in cotton-top tamarin," Gastroenterology, vol. 114, no. 4 I, pp. 669-674, 1998.

[79] J. D. Wood, O. C. Peck, K. S. Tefend et al., "Colitis and colon cancer in cotton-top tamarins (Saguinus oedipus oedipus) living wild in their natural habitat," Digestive Diseases and Sciences, vol. 43, no. 7, pp. 1443-1453, 1998.

[80] K. G. Mansfield, K. C. Lin, D. Xia et al., "Enteropathogenic Escherichia coli and ulcerative colitis in cotton-top tamarins (Saguinus oedipus)," Journal of Infectious Diseases, vol. 184, no. 6, pp. 803-807, 2001.

[81] P. E. Watkins, B. F. Warren, S. Stephens, P. Ward, and R. Foulkes, "Treatment of ulcerative colitis in the cottontop tamarin using antibody to tumour necrosis factor alpha," Gut, vol. 40, no. 5, pp. 628-633, 1997.

[82] S. B. Hanauer, B. G. Feagan, G. R. Lichtenstein et al., "Maintenance infliximab for Crohn's disease: the ACCENT I randomised trial," Lancet, vol. 359, no. 9317, pp. 1541-1549, 2002.

[83] P. Rutgeerts, R. H. Diamond, M. Bala et al., "Scheduled maintenance treatment with infliximab is superior to episodic treatment for the healing of mucosal ulceration associated with Crohn's disease," Gastrointestinal Endoscopy, vol. 63, no. 3, pp. 433-442, 2006.

[84] B. E. Sands, F. H. Anderson, C. N. Bernstein et al., "Infliximab maintenance therapy for fistulizing Crohn's disease," New England Journal of Medicine, vol. 350, no. 9, pp. 876-885, 2004.
[85] S. Ghosh, E. Goldin, F. H. Gordon et al., "Natalizumab for active Crohn's disease," New England Journal of Medicine, vol. 348, no. 1, pp. 24-32, 2003.

[86] W. J. Sandborn, J. F. Colombel, R. Enns et al., "Natalizumab induction and maintenance therapy for Crohn's disease," New England Journal of Medicine, vol. 353, no. 18, pp. 19121925, 2005.

[87] G. van Assche, M. van Ranst, R. Sciot et al., "Progressive multifocal leukoencephalopathy after natalizumab therapy for Crohn's disease," New England Journal of Medicine, vol. 353, no. 4, pp. 362-368, 2005.

[88] D. K. Podolsky, "Selective adhesion-molecule therapy and inflammatory bowel disease-a tale of Janus?" New England Journal of Medicine, vol. 353, no. 18, pp. 1965-1968, 2005.

[89] K. W. Ashi, T. Inagaki, Y. Fujimoto, and Y. Fukuda, "Induction by degraded carrageenan of colorectal tumors in rats," Cancer Letters, vol. 4, no. 3, pp. 171-176, 1978.

[90] Y. Oohashi, T. Ishioka, K. Wakabayashi, and N. Kuwabara, "A study on carcinogenesis induced by degraded carrageenan arising from squamous metaplasia of the rat colorectum," Cancer Letters, vol. 14, no. 3, pp. 267-272, 1981.

[91] T. Ishioka, N. Kuwabara, Y. Oohashi, and K. Wakabayashi, "Induction of colorectal tumors in rats by sulfated polysaccharides," Critical Reviews in Toxicology, vol. 17, no. 3, pp. 215-244, 1987.

[92] J. K. Tobacman, "Review of harmful gastrointestinal effects of carrageenan in animal experiments," Environmental Health Perspectives, vol. 109, no. 10, pp. 983-994, 2001.

[93] C. Benard, A. Cultrone, C. Michel et al., "Degraded carrageenan causing colitis in rats induces TNF secretion and ICAM-1 upregulation in monocytes through NF- $\kappa$ B activation," PLoS ONE, vol. 5, no. 1, article e8666, 2010.

[94] A. M. Chromik, A. M. Müller, M. Albrecht et al., "Oral administration of Taurolidine ameliorates chronic DSS colitis in mice," Journal of Investigative Surgery, vol. 20, no. 5, pp. 273-282, 2007.

[95] Y. J. Kim, K. S. Hong, J. W. Chung, J. H. Kim, and K. B. Hahm, "Prevention of colitis-associated carcinogenesis with infliximab," Cancer Prevention Research, vol. 3, no. 10, pp. 1314-1333, 2010.

[96] D. N. Seril, J. Liao, K. L. K. Ho, A. Warsi, C. S. Yang, and G. Y. Yang, "Dietary iron supplementation enhances DSS-induced colitis and associated colorectal carcinoma development in mice," Digestive Diseases and Sciences, vol. 47, no. 6, pp. 12661278, 2002.

[97] I. Okayasu, M. Yamada, T. Mikami, T. Yoshida, J. Kanno, and T. Ohkusa, "Dysplasia and carcinoma development in a repeated dextran sulfate sodium-induced colitis model," Journal of Gastroenterology and Hepatology, vol. 17, no. 10, pp. 1078-1083, 2002.

[98] H. S. Cooper, L. Everley, W. Chang et al., "The role of mutant Apc in the development of dysplasia and cancer in the mouse model of dextran sulfate sodium-induced colitis," Gastroenterology, vol. 121, no. 6, pp. 1407-1416, 2001.

[99] F. Kullmann, H. Messmann, M. Alt et al., "Clinical and histopathological features of dextran sulfate sodium induced acute and chronic colitis associated with dysplasia in rats," International Journal of Colorectal Disease, vol. 16, no. 4, pp. 238-246, 2001.

[100] H. S. Cooper, S. Murthy, K. Kido, H. Yoshitake, and A. Flanigan, "Dysplasia and cancer in the dextran sulfate sodium mouse colitis model. Relevance to colitis-associated 
neoplasia in the human: a study of histopathology, Bcatenin and p53 expression and the role of inflammation," Carcinogenesis, vol. 21, no. 4, pp. 757-768, 2000.

[101] T. Tanaka, H. Kohno, R. Suzuki, Y. Yamada, S. Sugie, and H. Mori, "A novel inflammation-related mouse colon carcinogenesis model induced by azoxymethane and dextran sodium sulfate," Cancer Science, vol. 94, no. 11, pp. 965-973, 2003.

[102] D. W. Rosenberg, C. Giardina, and T. Tanaka, "Mouse models for the study of colon carcinogenesis," Carcinogenesis, vol. 30, no. 2, pp. 183-196, 2009.

[103] T. Tanaka and R. Yasui, "Preclinical animal studies on chemoprevention of colorectal cancer," Clinical Gastroenterology, vol. 23, pp. 1669-1676, 2008.

[104] H. Kohno, R. Suzuki, S. Sugie, and T. Tanaka, " $\beta$-Catenin mutations in a mouse model of inflammation-related colon carcinogenesis induced by 1,2-dimethylhydrazine and dextran sodium sulfate," Cancer Science, vol. 96, no. 2, pp. 69-76, 2005.

[105] T. Tanaka, R. Suzuki, H. Kohno, S. Sugie, M. Takahashi, and K. Wakabayashi, "Colonic adenocarcinomas rapidly induced by the combined treatment with 2-amino-1-methyl6-phenylimidazo[4,5-b]pyridine and dextran sodium sulfate in male ICR mice possess $\beta$-catenin gene mutations and increases immunoreactivity for $\beta$-catenin, cyclooxygenase- 2 and inducible nitric oxide synthase," Carcinogenesis, vol. 26, no. 1, pp. 229-238, 2005.

[106] D. N. Seril, J. Liao, K. L. K. Ho, C. S. Yang, and G. Y. Yang, "Inhibition of chronic ulcerative colitis-associated colorectal adenocarcinoma development in a murine model by $\mathrm{N}$ acetylcysteine," Carcinogenesis, vol. 23, no. 6, pp. 993-1001, 2002.

[107] D. N. Seril, J. Liao, G. Y. Yang, and C. S. Yang, "Oxidative stress and ulcerative colitis-associated carcinogenesis: studies in humans and animal models," Carcinogenesis, vol. 24, no. 3, pp. 353-362, 2003.

[108] D. N. Seril, J. Liao, A. B. West, and G. Y. Yang, "High-iron diet: Foe or feat in ulcerative colitis and ulcerative colitisassociated carcinogenesis," Journal of Clinical Gastroenterology, vol. 40, no. 5, pp. 391-397, 2006.

[109] R. G. Hardy, S. J. Meltzer, and J. A. Jankowski, "ABC of colorectal cancer: molecular basis for risk factors," British Medical Journal, vol. 321, no. 7265, pp. 886-889, 2000.

[110] K. Makiyama, F. Takeshima, and T. Hamamoto, "Efficacy of rebamipide enemas in active distal ulcerative colitis and proctitis: a prospective study report," Digestive Diseases and Sciences, vol. 50, no. 12, pp. 2323-2329, 2005.

[111] T. Tanaka, H. Kohno, R. Suzuki et al., "Dextran sodium sulfate strongly promotes colorectal carcinogenesis in $\mathrm{Apc}^{\mathrm{Min} /+}$ mice: inflammatory stimuli by dextran sodium sulfate results in development of multiple colonic neoplasms," International Journal of Cancer, vol. 118, no. 1, pp. 25-34, 2006.

[112] S. P. Hussain, P. Amstad, K. Raja et al., "Increased p53 mutation load in noncancerous colon tissue from ulcerative colitis: a cancer-prone chronic inflammatory disease," Cancer Research, vol. 60, no. 13, pp. 3333-3337, 2000.

[113] G. C. Burmer, D. A. Crispin, V. R. Kolli et al., "Frequent loss of a p53 allele in carcinomas and their precursors in ulcerative colitis," Cancer Communications, vol. 3, no. 6, pp. 167-172, 1991.

[114] W. C. I. Chang, R. A. Coudry, M. I. Clapper et al., "Loss of p53 enhances the induction of colitis-associated neoplasia by dextran sulfate sodium," Carcinogenesis, vol. 28, no. 11, pp. 2375-2381, 2007.
[115] S. Fujii, T. Fujimori, H. Kawamata et al., "Development of colonic neoplasia in p53 deficient mice with experimental colitis induced by dextran sulphate sodium," Gut, vol. 53, no. 5, pp. 710-716, 2004.

[116] D. A. Wink, Y. Vodovotz, J. Laval, F. Laval, M. W. Dewhirst, and J. B. Mitchell, "The multifaceted roles of nitric oxide in cancer," Carcinogenesis, vol. 19, no. 5, pp. 711-721, 1998.

[117] M. Jaiswal, N. F. LaRusso, and G. J. Gores, "Nitric oxide in gastrointestinal epithelial cell carcinogenesis: linking inflammation to oncogenesis," American Journal of PhysiologyGastrointestinal and Liver Physiology, vol. 281, no. 3, pp. G626-G634, 2001.

[118] D. N. Seril, J. Liao, and G. Y. Yang, "Colorectal carcinoma development in inducible nitric oxide synthase-deficient mice with dextran sulfate sodium-induced ulcerative colitis," Molecular Carcinogenesis, vol. 46, no. 5, pp. 341-353, 2007.

[119] A. S. Fleisher, M. Esteller, N. Harpaz et al., "Microsatellite instability in inflammatory bowel disease-associated neoplastic lesions is associated with hypermethylation and diminished expression of the DNA mismatch repair gene, hMLH1," Cancer Research, vol. 60, no. 17, pp. 4864-4868, 2000.

[120] L. Cawkwell, F. Sutherland, H. Murgatroyd et al., "Defective hMSH2/hMLH1 protein expression is seen infrequently in ulcerative colitis associated colorectal cancers," Gut, vol. 46, no. 3, pp. 367-369, 2000.

[121] M. R. J. Kohonen-Corish, J. J. Daniel, H. te Riele, G. D. Buffinton, and J. E. Dahlstrom, "Susceptibility of Msh2-deficient mice to inflammation-associated colorectal tumors," Cancer Research, vol. 62, no. 7, pp. 2092-2097, 2002.

[122] E. Mizoguchi, "Chitinase 3-like-1 exacerbates intestinal inflammation by enhancing bacterial adhesion and invasion in colonic epithelial cells," Gastroenterology, vol. 130, no. 2, pp. 398-411, 2006.

[123] I. G. Barrison, P. D. Roberts, and S. P. Kane, "Oral or parenteral iron treatment in chronic ulcerative colitis?" British Medical Journal, vol. 282, no. 6275, p. 1514, 1981.

[124] J. M. Ward, "Morphogenesis of chemically induced neoplasms of the colon and small intestine in rats," Laboratory Investigation, vol. 30, no. 4, pp. 505-513, 1974.

[125] R. N. DuBois, A. Radhika, B. S. Reddy, and A. J. Entingh, "Increased cyclooxygenase-2 levels in carcinogen-induced rat colonic tumors," Gastroenterology, vol. 110, no. 4, pp. 1259$1262,1996$.

[126] K. Guda, C. Giardina, P. Nambiar, H. Cui, and D. W. Rosenberg, "Aberrant transforming growth factor- $\beta$ signaling in azoxymethane-induced mouse colon tumors," Molecular Carcinogenesis, vol. 31, no. 4, pp. 204-213, 2001.

[127] N. K. Relan, A. Saeed, K. Ponduri, S. E. G. Fligiel, S. Dutta, and A. P. N. Majumdar, "Identification and evaluation of the role of endogenous tyrosine kinases in azoxymethane induction of proliferative processes in the colonic mucosa of rats," Biochimica et Biophysica Acta, vol. 1244, no. 2-3, pp. 368-376, 1995.

[128] T. Tanaka, "Colorectal carcinogenesis: review of human and experimental animal studies," Journal of Carcinogenesis, vol. 8, article 5, 2009.

[129] J. M. Uronis, M. Mühlbauer, H. H. Herfarth, T. C. Rubinas, G. S. Jones, and C. Jobin, "Modulation of the intestinal microbiota alters colitis-associated colorectal cancer susceptibility," PLoS ONE, vol. 4, no. 6, article e6026, 2009.

[130] A. Borthakur, S. Bhattacharyya, P. K. Dudeja, and J. K. Tobacman, "Carrageenan induces interleukin-8 production through distinct Bcl10 pathway in normal human 
colonic epithelial cells," American Journal of PhysiologyGastrointestinal and Liver Physiology, vol. 292, no. 3, pp. G829-G838, 2007.

[131] S. Bhattacharyya, P. K. Dudeja, and J. K. Tobacman, "Carrageenan-induced NFאB activation depends on distinct pathways mediated by reactive oxygen species and Hsp27 or by Bcl10," Biochimica et Biophysica Acta, vol. 1780, no. 7-8, pp. 973-982, 2008.

[132] D. Wallach, E. E. Varfolomeev, N. L. Malinin, Y. V. Goltsev, A. V. Kovalenko, and M. P. Boldin, "Tumor necrosis factor receptor and Fas signaling mechanisms," Annual Review of Immunology, vol. 17, pp. 331-367, 1999.

[133] F. X. Pimentel-Muiños and B. Seed, "Regulated commitment of TNF receptor signaling: a molecular switch for death or activation," Immunity, vol. 11, no. 6, pp. 783-793, 1999.

[134] B. K. Popivanova, F. I. Kostadinova, K. Furuichi et al., "Blockade of a chemokine, CCL2, reduces chronic colitisassociated carcinogenesis in mice," Cancer Research, vol. 69, no. 19, pp. 7884-7892, 2009.

[135] S. I. Grivennikov, D. V. Kuprash, Z. Liu, and S. A. Nedospasov, "Intracellular signals and events activated by cytokines of the tumor necrosis factor superfamily: from simple paradigms to complex mechanisms," International Review of Cytology, vol. 252, pp. 129-161, 2006.

[136] P. Rutgeerts, G. van Assche, and S. Vermeire, "Optimizing anti-TNF treatment in inflammatory bowel disease," Gastroenterology, vol. 126, no. 6, pp. 1593-1610, 2004.

[137] K. Peppel, D. Crawford, and B. Beutler, "A tumor necrosis factor (TNF) receptor-IgG heavy chain chimeric protein as a bivalent antagonist of TNF activity," Journal of Experimental Medicine, vol. 174, no. 6, pp. 1483-1489, 1991.

[138] E. Burstein and E. R. Fearon, "Colitis and cancer: a tale of inflammatory cells and their cytokines," Journal of Clinical Investigation, vol. 118, no. 2, pp. 464-467, 2008.

[139] T. Bongartz, A. J. Sutton, M. J. Sweeting, I. Buchan, E. L. Matteson, and V. Montori, "Anti-TNF antibody therapy in rheumatoid arthritis and the risk of serious infections and malignancies: systematic review and meta-analysis of rare harmful effects in randomized controlled trials," Journal of the American Medical Association, vol. 295, no. 19, pp. 22752285, 2006.

[140] L. Biancone, C. Petruzziello, E. Calabrese et al., "Longterm safety of Infliximab for the treatment of inflammatory bowel disease: does blocking TNF $\alpha$ reduce colitis-associated colorectal carcinogenesis?" Gut, vol. 58, no. 12, article 1703, 2009.

[141] K. Hoebe, E. Janssen, and B. Beutler, "The interface between innate and adaptive immunity," Nature Immunology, vol. 5, no. 10, pp. 971-974, 2004.

[142] P. C. Heinrich, I. Behrmann, G. Muller-Newen, F. Schaper, and L. Graeve, "Interleukin-6-type cytokine signalling through the gp130/Jak/STAT pathway," Biochemical Journal, vol. 334, part 2, pp. 297-314, 1998.

[143] M. Veldhoen, R. J. Hocking, C. J. Atkins, R. M. Locksley, and B. Stockinger, "TGF $\beta$ in the context of an inflammatory cytokine milieu supports de novo differentiation of IL-17producing T cells," Immunity, vol. 24, no. 2, pp. 179-189, 2006.

[144] M. O. Li, Y. Y. Wan, and R. A. Flavell, "T cell-produced transforming growth factor- $\beta 1$ controls $\mathrm{T}$ cell tolerance and regulates Th1- and Th17-cell differentiation," Immunity, vol. 26, no. 5, pp. 579-591, 2007.
[145] R. Atreya, J. Mudter, S. Finotto et al., "Blockade of interleukin 6 trans signaling suppresses T-cell resistance against apoptosis in chronic intestinal inflammation: evidence in Crohn disease and experimental colitis in vivo," Nature Medicine, vol. 6, no. 5, pp. 583-588, 2000.

[146] M. Yamamoto, K. Yoshizaki, T. Kishimoto, and H. Ito, "IL-6 is required for the development of Th1 cell-mediated murine colitis," Journal of Immunology, vol. 164, no. 9, pp. 48784882, 2000.

[147] D. Yen, J. Cheung, H. Scheerens et al., "IL-23 is essential for T cell-mediated colitis and promotes inflammation via IL-17 and IL-6," Journal of Clinical Investigation, vol. 116, no. 5, pp. 1310-1316, 2006.

[148] M. Noguchi, N. Hiwatashi, Z. Liu, and T. Toyota, "Secretion imbalance between tumour necrosis factor and its inhibitor in inflammatory bowel disease," Gut, vol. 43, no. 2, pp. 203209, 1998.

[149] I. Okayasu, M. Yamada, T. Mikami, T. Yoshida, J. Kanno, and T. Ohkusa, "Dysplasia and carcinoma development in a repeated dextran sulfate sodium-induced colitis model," Journal of Gastroenterology and Hepatology, vol. 17, no. 10, pp. 1078-1083, 2002.

[150] K. Mitsuyama, S. Matsumoto, S. Rose-John et al., "STAT3 activation via interleukin 6 trans-signalling contributes to ileitis in SAMP1/Yit mice," Gut, vol. 55, no. 9, pp. 1263-1269, 2006.

[151] H. Ito, M. Takazoe, Y. Fukuda et al., "A pilot randomized trial of a human anti-interleukin-6 receptor monoclonal antibody in active Crohn's disease," Gastroenterology, vol. 126, no. 4, pp. 989-996, 2004.

[152] J. I. Fenton, S. D. Hursting, S. N. Perkins, and N. G. Hord, "Interleukin-6 production induced by leptin treatment promotes cell proliferation in an Apc (Min/+) colon epithelial cell line," Carcinogenesis, vol. 27, no. 7, pp. 1507-1515, 2006.

[153] C. Becker, M. C. Fantini, S. Wirtz et al., "IL-6 signaling promotes tumor growth in colorectal cancer," Cell Cycle, vol. 4, no. 2, pp. 217-220, 2005.

[154] Y. C. Chung and Y. F. Chang, "Serum interleukin-6 levels reflect the disease status of colorectal cancer," Journal of Surgical Oncology, vol. 83, no. 4, pp. 222-226, 2003.

[155] H. Yu, D. Pardoll, and R. Jove, "STATs in cancer inflammation and immunity: a leading role for STAT3," Nature Reviews Cancer, vol. 9, no. 11, pp. 798-809, 2009.

[156] J. Bollrath, T. J. Phesse, V. A. von Burstin et al., "gp130mediated stat 3 activation in enterocytes regulates cell survival and cell-cycle progression during colitis-associated tumorigenesis," Cancer Cell, vol. 15, no. 2, pp. 91-102, 2009.

[157] R. Atreya and M. F. Neurath, "Involvement of IL-6 in the pathogenesis of inflammatory bowel disease and colon cancer," Clinical Reviews in Allergy and Immunology, vol. 28, no. 3, pp. 187-195, 2005.

[158] W. E. Naugler and M. Karin, “The wolf in sheep's clothing: the role of interleukin- 6 in immunity, inflammation and cancer," Trends in Molecular Medicine, vol. 14, no. 3, pp. 109119, 2008.

[159] C. Becker, M. C. Fantini, C. Schramm et al., "TGF- $\beta$ suppresses tumor progression in colon cancer by inhibition of IL-6 trans-signaling," Immunity, vol. 21, no. 4, pp. 491501, 2004.

[160] YI. Li, C. de Haar, M. Chen et al., "Disease-related expression of the IL6/STAT3/SOCS3 signalling pathway in ulcerative colitis and ulcerative colitis-related carcinogenesis," Gut, vol. 59, no. 2, pp. 227-235, 2010. 
[161] C. S. R. Lankford and D. M. Frucht, "A unique role for IL-23 in promoting cellular immunity," Journal of Leukocyte Biology, vol. 73, no. 1, pp. 49-56, 2003.

[162] C. Abraham and J. H. Cho, "IL-23 and autoimmunity: new insights into the pathogenesis of inflammatory bowel disease," Annual Review of Medicine, vol. 60, pp. 97-110, 2009.

[163] P. P. Ahern, A. Izcue, K. J. Maloy, and F. Powrie, "The interleukin-23 axis in intestinal inflammation," Immunological Reviews, vol. 226, no. 1, pp. 147-159, 2008.

[164] J. L. Langowski, X. Zhang, L. Wu et al., "IL-23 promotes tumour incidence and growth," Nature, vol. 442, no. 7101, pp. 461-465, 2006.

[165] B. E. Shan, J. S. Hao, Q. X. Li, and M. Tagawa, "Antitumor activity and immune enhancement of murine interleukin23 expressed in murine colon carcinoma cells," Cellular \& Molecular Immunology, vol. 3, no. 1, pp. 47-52, 2006.

[166] W. Shen and S. K. Durum, "Synergy of IL-23 and Th17 cytokines: new light on inflammatory bowel disease," Neurochemical Research, vol. 35, no. 6, pp. 940-946, 2010.

[167] M. Oshima, H. Oshima, K. Kitagawa, M. Kobayashi, C. Itakura, and M. Taketo, "Loss of Apc heterozygosity and abnormal tissue building in nascent intestinal polyps in mice carrying a truncated Apc gene," Proceedings of the National Academy of Sciences of the United States of America, vol. 92, no. 10, pp. 4482-4486, 1995.

[168] M. Fukata, A. Chen, A. Klepper et al., "Cox-2 is regulated by Toll-like receptor-4 (TLR4) signaling: role in proliferation and apoptosis in the intestine," Gastroenterology, vol. 131, no. 3, pp. 862-877, 2006.

[169] Y. Hernandez, J. Sotolongo, K. Breglio et al., "The role of prostaglandin E2(PGE 2) in Toll-like receptor 4 (TLR4)mediated colitis-associated neoplasia," BMC Gastroenterology, vol. 10, article 82, 2010.

[170] M. M. Taketo, "COX-2 and colon cancer," Inflammation Research, vol. 47, no. 2, pp. S112-S116, 1998.

[171] K. Mukawa, S. Fujii, K. Tominaga et al., "Inhibitory effects of the cyclooxygenase-2 inhibitor, etodolac, on colitisassociated tumorigenesis in p53-deficient mice treated with dextran sulfate sodium," Oncology Reports, vol. 19, no. 2, pp. 393-399, 2008.

[172] C. J. Grubbs, R. A. Lubet, A. T. Koki et al., "Celecoxib inhibits N-butyl-N-(4-hydroxybutyl)-nitrosamine-induced urinary bladder cancers in male B6D2F1 mice and female Fischer-344 rats," Cancer Research, vol. 60, no. 20, pp. 5599$5602,2000$.

[173] G. D. Basu, L. B. Pathangey, T. L. Tinder, S. J. Gendler, and P. Mukherjee, "Mechanisms underlying the growth inhibitory effects of the cyclo-oxygenase-2 inhibitor celecoxib in human breast cancer cells," Breast Cancer Research, vol. 7, no. 4, pp. R422-435, 2005.

[174] J. Lin, P. W. Hsiao, T. H. Chiu, and J. I. Chao, "Combination of cyclooxygenase-2 inhibitors and oxaliplatin increases the growth inhibition and death in human colon cancer cells," Biochemical Pharmacology, vol. 70, no. 5, pp. 658-667, 2005.

[175] A. Haynes, M. S. Shaik, A. Chatterjee, and M. Singh, "Formulation and evaluation of aerosolized celecoxib for the treatment of lung cancer," Pharmaceutical Research, vol. 22, no. 3, pp. 427-439, 2005.

[176] S. D. Solomon, M. A. Pfeffer, J. J. V. McMurray et al., "Effect of celecoxib on cardiovascular events and blood pressure in two trials for the prevention of colorectal adenomas," Circulation, vol. 114, no. 10, pp. 1028-1035, 2006.
[177] S. D. Solomon, J. Wittes, P. V. Finn et al., "Cardiovascular risk of celecoxib in 6 randomized placebo-controlled trials: the cross trial safety analysis," Circulation, vol. 117, no. 16, pp. 2104-2113, 2008.

[178] C. Bosetti, S. Gallus, and C. La Vecchia, "Aspirin and cancer risk: an update to 2001," European Journal of Cancer Prevention, vol. 11, no. 6, pp. 535-542, 2002.

[179] J. A. Baron, B. F. Cole, R. S. Sander et al., "A randomized trial of aspirin to prevent colorectal adenomas. A randomized trial od aspirin to prevent colorectal adenomas," New England Journal of Medicine, vol. 40, pp. 289-292, 2003.

[180] R. S. Sandler, S. Halabi, J. A. Baron et al., "A randomized trial of aspirin to prevent colorectal adenomas in patients with previous colorectal cancer," New England Journal of Medicine, vol. 348, no. 10, pp. 883-890, 2003.

[181] P. A. Craven and F. R. DeRubertis, "Effects of aspirin on 1,2-dimethylhydrazine-induced colonic carcinogenesis," Carcinogenesis, vol. 13, no. 4, pp. 541-546, 1992.

[182] B. S. Reddy, C. V. Rao, A. Rivenson, and G. Kelloff, "Inhibitory effect of aspirin on azoxymethane-induced colon carcinogenesis in F344 rats," Carcinogenesis, vol. 14, no. 8, pp. 1493-1497, 1993.

[183] N. N. Mahmoud, A. J. Dannenberg, J. Mestre et al., “Aspirin prevents tumors in a murine model of familial adenomatous polyposis," Surgery, vol. 124, no. 2, pp. 225-231, 1998.

[184] J. Paterson, G. Baxter, J. Lawrence, and G. Duthie, "Is there a role for dietary salicylates in health?" Proceedings of the Nutrition Society, vol. 65, no. 1, pp. 93-96, 2006.

[185] S. Pestka, C. D. Krause, D. Sarkar, M. R. Walter, Y. Shi, and P. B. Fisher, "Interleukin-10 and related cytokines and receptors," Annual Review of Immunology, vol. 22, pp. 929979, 2004.

[186] A. S. Ho, S. H. Wei, A. L. Mui, A. Miyajima, and K. W. Moore, "Functional regions of the mouse interleukin-10 receptor expression on human natural killer cells," Blood, vol. 85, pp. 3577-3585, 1995.

[187] R. Kuhn, J. Lohler, D. Rennick, K. Rajewski, and W. Muller, "Interleukin-10-deficient mice develop chronic colonic enterocolitis," Cell, vol. 75, pp. 263-274, 1993.

[188] W. G. Stetler-Stevenson, S. Aznavoorian, and L. A. Liotta, "Tumor cell interactions with the extracellular matrix during invasion and metastasis," Annual Review of Cell Biology, vol. 9, pp. 541-573, 1993.

[189] N. Khalil, "TGF- $\beta$ : from latent to active," Microbes and Infection, vol. 1, no. 15, pp. 1255-1263, 1999.

[190] M. C. Fantini, C. Becker, G. Monteleone, F. Pallone, P. R. Galle, and M. F. Neurath, "Cutting edge: TGF- $\beta$ induces a regulatory phenotype in $\mathrm{CD} 4+\mathrm{CD} 25-\mathrm{T}$ cells through Foxp3 induction and down-regulation of Smad7," Journal of Immunology, vol. 172, no. 9, pp. 5149-5153, 2004.

[191] D. Hanahan and R. A. Weinberg, "The hallmarks of cancer," Cell, vol. 100, no. 1, pp. 57-70, 2000.

[192] G. C. Blobe, W. P. Schiemann, and H. F. Lodish, "Role of transforming growth factor $\beta$ in human disease," New England Journal of Medicine, vol. 342, no. 18, pp. 1350-1358, 2000.

[193] S. J. Engle, I. Ormsby, S. Pawlowski et al., "Elimination of colon cancer in germ-free transforming growth factor beta 1-deficient mice," Cancer Research, vol. 62, no. 22, pp. 63626366, 2002.

[194] D. Leroith and C. T. Roberts, "Insulin-like growth factors," Annals of the New York Academy of Sciences, vol. 692, pp. 1-9, 1993. 
[195] D. Germs and L. Partridge, "Insulin/IGF signaling and ageing:seeing the bigger picture," Current Opinion in Genetics \& Development, vol. 11, pp. 287-292, 2001.

[196] E. Foulstone, S. Prince, O. Zaccheo et al., "Insulin-like growth factor ligands, receptors, and binding proteins in cancer," Journal of Pathology, vol. 205, no. 2, pp. 145-153, 2005.

[197] A. P. Feinberg and B. Tycko, "The history of cancer epigenetics," Nature Reviews Cancer, vol. 4, no. 2, pp. 143-153, 2004.

[198] H. Cui, P. Onyango, S. Brandenburg, Y. Wu, C. L. Hsieh, and A. P. Feinberg, "Loss of imprinting in colorectal cancer linked to hypomethylation of H19 and IGF2," Cancer Research, vol. 62, no. 22, pp. 6442-6446, 2002.

[199] H. Cui, M. Cruz-Correa, F. M. Giardiello et al., "Loss of IGF2 imprinting: a potential marker of colorectal cancer risk," Science, vol. 299, no. 5613, pp. 1753-1755, 2003.

[200] T. Sakatani, A. Kaneda, C. A. Iacobuzio-Donahue et al., "Loss of imprinting of Igf2 alters intestinal maturation and tumorigenesis in mice," Science, vol. 307, no. 5717, pp. 19761978, 2005.

[201] A. Kaneda, C. J. Wang, R. Cheong et al., "Enhanced sensitivity to IGF-II signaling links loss of imprinting of IGF2 to increased cell proliferation and tumor risk," Proceedings of the National Academy of Sciences of the United States of America, vol. 104, no. 52, pp. 20926-20931, 2007.

[202] E. K. Maloney, J. L. McLaughlin, N. E. Dagdigian et al., "An anti-insulin-like growth factor I receptor antibody that is a potent inhibitor of cancer cell proliferation," Cancer Research, vol. 63, no. 16, pp. 5073-5083, 2003.

[203] C. S. Mitsiades, N. S. Mitsiades, C. J. McMullan et al., "Inhibition of the insulin-like growth factor receptor-1 tyrosine kinase activity as a therapeutic strategy for multiple myeloma, other hematologic malignancies, and solid tumors," Cancer Cell, vol. 5, no. 3, pp. 221-230, 2004.

[204] G. Carpenter and S. Cohen, "Epidermal growth factor," Journal of Biological Chemistry, vol. 265, no. 14, pp. 77097712, 1990.

[205] L. Cawkwell, F. Sutherland, H. Murgatroyd et al., "Defective $\mathrm{hMSH} 2 / \mathrm{hMLH} 1$ protein expression is seen infrequently in ulcerative colitis associated colorectal cancers," Gut, vol. 46, no. 3, pp. 367-369, 2000.

[206] R. S. Herbst, "Review of epidermal growth factor receptor biology," International Journal of Radiation Oncology Biology Physics, vol. 59, no. 2, pp. 21-26, 2004.

[207] A. Sinha, J. Nightingale, K. P. West, J. Berlanga-Acosta, and R. J. Playford, "Epidermal growth factor enemas with oral mesalamine for mild-to-moderate left-sided ulcerative colitis or proctitis," New England Journal of Medicine, vol. 349, no. 4, pp. 350-357, 2003.

[208] O. Bashir, A. J. Fitzgerald, J. Berlanga-Acosta, R. J. Playford, and R. A. Goodlad, "Effect of epidermal growth factor administration on intestinal cell proliferation, crypt fission and polyp formation in multiple intestinal neoplasia (Min) mice," Clinical Science, vol. 105, no. 3, pp. 323-330, 2003.

[209] A. Fichera, N. Little, S. Jagadeeswaran et al., "Epidermal growth factor receptor signaling is required for microadenoma formation in the mouse azoxymethane model of colonic carcinogenesis," Cancer Research, vol. 67, no. 2, pp. 827-835, 2007.

[210] T. Hu and C. Li, "Convergence between Wnt- $\beta$-catenin and EGFR signaling in cancer," Molecular Cancer, vol. 9, pp. 236242, 2010.

[211] J.-A. Park, J. M. Drazen, and D. J. Tschumperlin, "The Chitinase-like protein YKL-40 is secreted by airway epithelial cells at base line and in response to compressive mechanical stress," Journal of Biological Chemistry, vol. 285, no. 39, pp. 29817-29825, 2010.

[212] R. Shao, K. Hamel, L. Petersen et al., "YKL-40, a secreted glycoprotein, promotes tumor angiogenesis," Oncogene, vol. 28, no. 50, pp. 4456-4468, 2009.

[213] G. Cohen, R. Mustafi, A. Chumsangsri et al., "Epidermal growth factor receptor signaling is up-regulated in human colonic aberrant crypt foci," Cancer Research, vol. 66, no. 11, pp. 5656-5664, 2006.

[214] Y. Liu, J. Ju, H. Xiao et al., "Effects of combination of calcium and aspirin on azoxymethane-induced aberrant crypt foci formation in the colons of mice and rats," Nutrition and Cancer, vol. 60, no. 5, pp. 660-665, 2008.

[215] M. J. Wargovich, D. Allnutt, C. Palmer, P. Anaya, and L. C. Stephens, "Inhibition of the promotional phase of azoxymethane-induced colon carcinogenesis in the F344 rat by calcium lactate: effect of simulating two human nutrient density levels," Cancer Letters, vol. 53, no. 1, pp. 17-25, 1990.

[216] M. J. Wargovich, P. M. Lynch, and B. Levin, "Modulating effects of calcium in animal models of colon carcinogenesis and short-term studies in subjects at increased risk for colon cancer," American Journal of Clinical Nutrition, vol. 54, no. 1, pp. 202S-205S, 1991.

[217] M. L. McCullough, A. S. Robertson, C. Rodriguez et al., "Calcium, vitamin D, dairy products, and risk of colorectal cancer in the Cancer Prevention Study II Nutrition Cohort (United States)," Cancer Causes and Control, vol. 14, no. 1, pp. 1-12, 2003.

[218] K. Wu, W. C. Willett, C. S. Fuchs, G. A. Colditz, and E. L. Giovannucci, "Calcium intake and risk of colon cancer in women and men," Journal of the National Cancer Institute, vol. 94, no. 6, pp. 437-446, 2002.

[219] P. Terry, J. A. Baron, L. Bergkvist, L. Holmberg, and A. Wolk, "Dietary calcium and vitamin D intake and risk of colorectal cancer: a prospective cohort study in women," Nutrition and Cancer, vol. 43, no. 1, pp. 39-46, 2002.

[220] Y. Park, M. F. Leitzmann, A. F. Subar, A. Hollenbeck, and A. Schatzkin, "Dairy food, calcium, and risk of cancer in the NIH-AARP diet and health study," Archives of Internal Medicine, vol. 169, no. 4, pp. 391-401, 2009.

[221] S. A. Lamprecht and M. Lipkin, "Cellular mechanisms of calcium and vitamin D in the inhibition of colorectal carcinogenesis," Annals of the New York Academy of Sciences, vol. 952, pp. 73-87, 2001.

[222] E. J. Fernandez and E. Lolis, "Structure, function, and inhibition of chemokines," Annual Review of Pharmacology and Toxicology, vol. 42, pp. 469-499, 2002.

[223] H. Wang, C. Czura, and K. Tracey, “TNF”, in The Cytokine Handbook, A. Thomson and M. Lotze, Eds., pp. 837-860, Elsevier Science, London, UK, 2003.

[224] C. Garlanda, F. Riva, T. Veliz et al., "Increased susceptibility to colitis-associated cancer of mice lacking TIR8, an inhibitory member of the interleukin-1 receptor family," Cancer Research, vol. 67, no. 13, pp. 6017-6021, 2007.

[225] D. Wang, H. Wang, J. Brown et al., "CXCL1 induced by prostaglandin E promotes angiogenesis in colorectal cancer," Journal of Experimental Medicine, vol. 203, no. 4, pp. 941951, 2006.

[226] K. Sakamoto and S. Maeda, "Targeting NF- $\kappa$ B for colorectal cancer," Expert Opinion on Therapeutic Targets, vol. 14, no. 6, pp. 593-601, 2010. 
[227] R. J. B. Nibbs, E. Kriehuber, P. D. Ponath et al., "The $\beta$ chemokine receptor D6 is expressed by lymphatic endothelium and a subset of vascular tumors," American Journal of Pathology, vol. 158, no. 3, pp. 867-877, 2001.

[228] M. Shahabuddin, T. Toyoshima, M. Aikawa, and D. C. Kaslow, "Transmission-blocking activity of a Chitinase inhibitor and activation of malarial parasite Chitinase by mosquito protease," Proceedings of the National Academy of Sciences of the United States of America, vol. 90, no. 9, pp. 4266-4270, 1993.

[229] B. Henrissat and G. Davies, "Structural and sequence-based classification of glycoside hydrolases," Current Opinion in Structural Biology, vol. 7, no. 5, pp. 637-644, 1997.

[230] B. E. Hakala, C. White, and A. D. Recklies, "Human cartilage gp-39, a major secretory product of articular chondrocytes and synovial cells, is a Mammalian member of a Chitinase protein family," Journal of Biological Chemistry, vol. 268, no. 34, pp. 25803-25810, 1993.

[231] R. G. Boot, E. F. C. Blommaart, E. Swart et al., "Identification of a novel acidic Mammalian Chitinase distinct from chitotriosidase," Journal of Biological Chemistry, vol. 276, no. 9, pp. 6770-6778, 2001.

[232] C. E. M. Hollak, S. van Weely, M. H. J. van Oers, and J. M. F. G. Aerts, "Marked elevation of plasma chitotriosidase activity. A novel hallmark of Gaucher disease," Journal of Clinical Investigation, vol. 93, no. 3, pp. 1288-1292, 1994.

[233] H. M. Jin, N. G. Copeland, D. J. Gilbert, N. A. Jenkins, R. B. Kirkpatrick, and M. Rosenberg, "Genetic characterization of the murine $\mathrm{Ym} 1$ gene and identification of a cluster of highly homologous genes," Genomics, vol. 54, no. 2, pp. 316-322, 1998.

[234] I. Vind, J. S. Johansen, P. A. Price, and P. Munkholm, "Serum YKL-40, a potential new marker of disease activity in patients with inflammatory bowel disease," Scandinavian Journal of Gastroenterology, vol. 38, no. 6, pp. 599-605, 2003.

[235] C. Cintin, J. S. Johansen, I. J. Christensen, P. A. Price, S. Sørensen, and H. J. Nielsen, "High serum YKL-40 level after surgery for colorectal carcinoma is related to short survival," Cancer, vol. 95, no. 2, pp. 267-274, 2002.

[236] J. S. Johansen, B. V. Jensen, A. Roslind, D. Nielsen, and P. A. Price, "Serum YKL-40, a new prognostic biomarker in cancer patients?" Cancer Epidemiology Biomarkers and Prevention, vol. 15, no. 2, pp. 194-202, 2006.

[237] J. S. Johansen, "Studies on serum YKL-40 as a biomarker in diseases with inflammation, tissue remodelling, fibroses and cancer," Danish Medical Bulletin, vol. 53, no. 2, pp. 172-209, 2006.

[238] H. F. Bigg, R. Wait, A. D. Rowan, and T. E. Cawston, "The Mammalian Chitinase-like lectin, YKL-40, binds specifically to type I collagen and modulates the rate of type I collagen fibril formation," Journal of Biological Chemistry, vol. 281, no. 30, pp. 21082-21095, 2006.

[239] F. Fusetti, T. Pijning, K. H. Kalk, E. Bos, and B. W. Dijkstra, "Crystal structure and carbohydrate-binding properties of the human cartilage glycoprotein-39," Journal of Biological Chemistry, vol. 278, no. 39, pp. 37753-37760, 2003.

[240] J. A. Park, J. M. Drazen, and D. J. Tschumperlin, "The Chitinase-like protein YKL-40 is secreted by airway epithelial cells at base line and in response to compressive mechanical stress," Journal of Biological Chemistry, vol. 285, no. 39, pp. 29817-29825, 2010. 


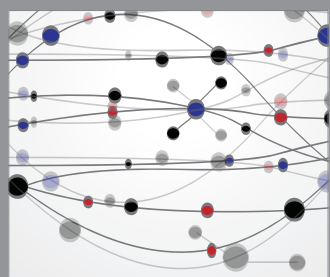

The Scientific World Journal
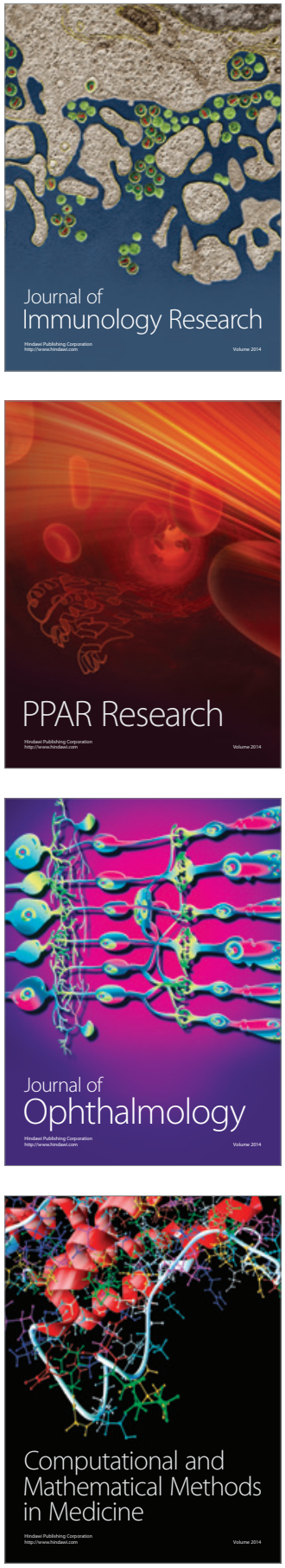

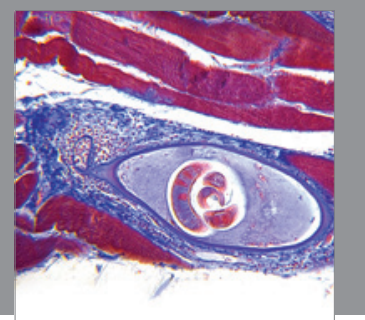

Gastroenterology

Research and Practice
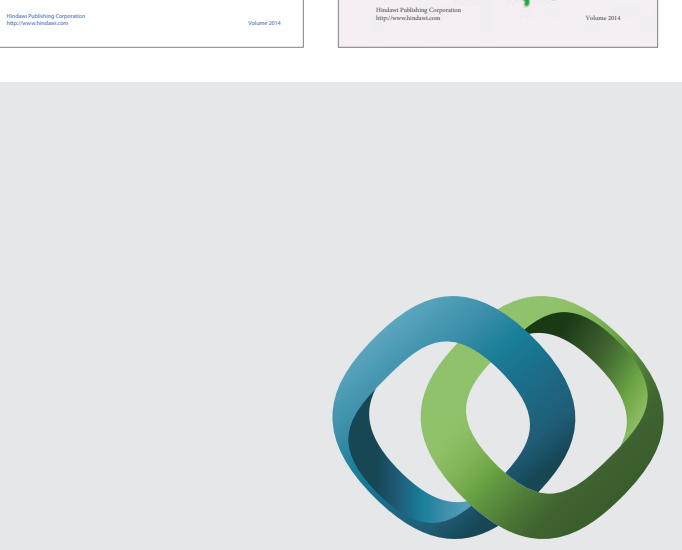

\section{Hindawi}

Submit your manuscripts at

http://www.hindawi.com
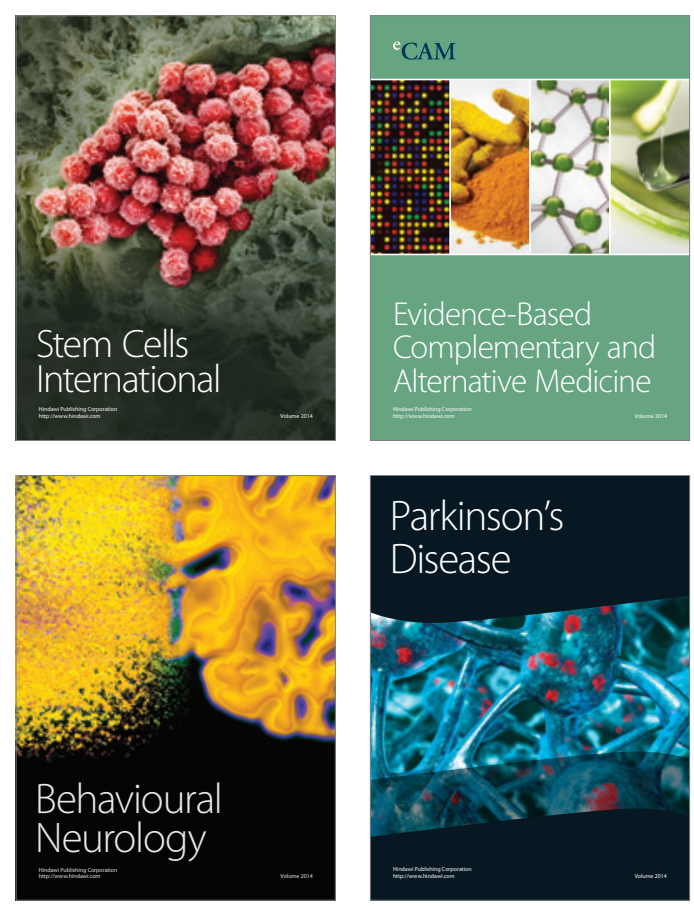

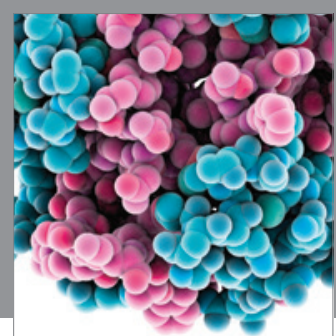

Journal of
Diabetes Research

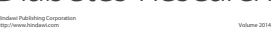

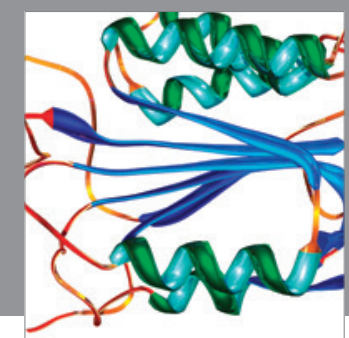

Disease Markers
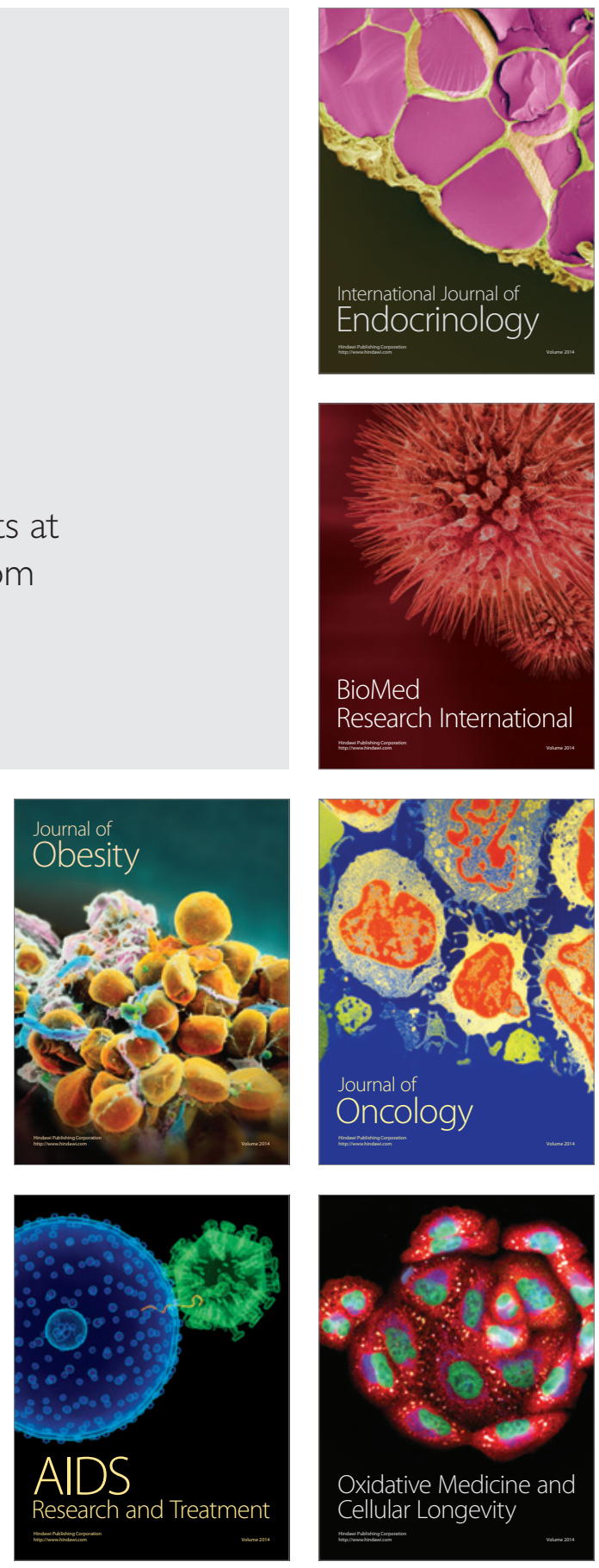